Discussion Paper No. 801

\title{
HOW AN EXPORT BOOM AFFECTS UNEMPLOYMENT
}

\author{
Noel Gaston \\ Gulasekaran Rajaguru
}

January 2011

The Institute of Social and Economic Research Osaka University

6-1 Mihogaoka, Ibaraki, Osaka 567-0047, Japan 


\title{
How an Export Boom affects Unemployment
}

\author{
Noel Gaston and Gulasekaran Rajaguru*
}

\begin{abstract}
Does trade affect the equilibrium rate of unemployment? To theoretically examine this question, we incorporate firm-union bargaining considerations into a model with a booming external sector and a stagnating manufacturing sector. In the model, a sustained improvement in the terms of trade lowers unemployment. To empirically investigate the predicted determinants of the unemployment rate, we use data for Australia, a country whose prosperity has always depended on the value of its exports. We find strong evidence that higher export prices, capital accumulation in tradeable goods industries and a lower unemployment benefit replacement rate each reduce the equilibrium unemployment rate.
\end{abstract}

Keywords: equilibrium unemployment rate, specific factors model, bargaining, mining boom, Dutch disease.

JEL Classification: E24, F12, J51.

* Globalisation and Development Centre and School of Business, Bond University, Gold Coast, Queensland 4229, Australia. Correspondence: ngaston@bond.edu.au. We thank Tilak Abeysinghe, Fabrice Collard, Xavier de Vanssay, Rod Falvey, Lance Fisher, Shravan Luckraz and Nic Sim as well as seminar participants at the University of Adelaide, University of Göttingen, Kansai Institute for Social and Economic Research, Keio University, Macquarie University, Monash University and the National Graduate Institute for Policy Studies for their comments. The first-named author would like to acknowledge the support and collegial atmosphere provided by the Institute for Social and Economic Research at Osaka University. The usual disclaimers apply. 


\section{Introduction}

Understanding the way in which external economic conditions and globalisation affect domestic labour markets has been a major research endeavour for economists for decades. More recently, the slow pace of recovery from the effects of the Global Financial Crisis (GFC) has further stimulated research on how trade affects unemployment. Two years after the onset of the Crisis, the rate of unemployment in many OECD countries remains stubbornly high. Those countries with more resilient economies seem to be those which are "exporting their way to recovery". In particular, the resilience seems to have a lot to do with high trade exposure to a robust Chinese economy.

As a small open economy, Australian prosperity has long depended on the strength of its exports. After peaking at over ten per cent in 1993, Australia's unemployment rate steadily fell until the onset of the GFC. The drop in the unemployment rate was particularly sharp during the years of Australia's mining boom. During the 2007 election campaign, the then (Coalition) government claimed that the falling unemployment rate was due to its superior economic management and deregulation of the labour market. The then (Labor) Opposition claimed that the good news on the unemployment front was primarily due to the booming demand for mining resources (and certainly not to any labour market reforms). It seems that being in government changes one's perspective. In response to the threat posed by the GFC, the Labor government embarked on a massive fiscal spending programme. Unemployment increased during the GFC, but only moderately. Compared to many of its OECD counterparts, Australia escaped relatively unscathed. Labor has been quick to claim credit for its stimulus spending. The Coalition opposition now argues that the strength of the Chinese economy has been the key.

This paper examines how a country's unemployment rate is affected by the demand for its exports. We use a specific factors model to examine the effect of changing terms of trade on the unemployment rate. This model of a small open economy has a perfectly (domestically) mobile factor and an immobile factor. Assuming the former to be labour implies that wages are equalised across sectors of the economy. Unemployment is generated in our model due to union-firm bargaining. Incorporating bargaining considerations into a specific factors model helps identify the effects of increases in the terms of trade as well as the capital stock in the export sector on the unemployment rate. In the model, these factors raise workers' wages (i.e., in all sectors of the economy) but, as we shall see, they also lower equilibrium unemployment. The theory is in the mould of models by Davidson et al. (1999), Hoon (2001a, 2001b), Kee and Hoon (2005), Moore and Ranjan (2005) and Helpman and Itskhoki (2010). These papers incorporate equilibrium unemployment into general equilibrium trade models to show how the unemployment rate is affected by international factors, including the terms of trade. ${ }^{1}$

\footnotetext{
${ }^{1}$ In their review of research on trade and labour markets, Davidson and Matusz (2011) discuss how a variety of labour market frictions are introduced into general equilibrium settings to generate unemployment. The prominent approaches are: implicit contract models, efficiency wage models, bargaining models and search or matching models. These models yield a wide variety of relationships between relative commodity prices and relative factor prices and between trade and unemployment. Unfortunately, the proliferation of models has not yielded a clearer picture as to whether greater trade openness is beneficial or detrimental to the equilibrium rate of unemployment.
} 
Moore and Ranjan (2005) show that increased trade with developing countries, as manifested by higher relative prices for skill-intensive goods, raises both unemployment and income inequality. In the case of Australia, exports are not skill-intensive and this may explain why higher terms of trade have lead to less income inequality (see Gaston and Rajaguru, 2009). One explanation for this finding is based on the fact that improved terms of trade raise producer prices (PPI) more than consumer prices (CPI) (see EEAG, 2008, p.86). If employment is determined by the real product wage (the nominal wage deflated by the PPI), then employment and nominal wages increase with improved terms of trade. We build on this insight by examining external trading conditions and the differential development of key sectors of the economy.

Our paper is also related to the substantial 'Dutch disease' literature. In particular, Cordon and Neary (1982) model the co-existence of a booming export sector and a declining or lagging import sector (taken to be manufacturing industry for most developed economies). Here the traditional concern is that de-industrialisation occurs due to the loss of mobile factors of production to the booming sector. In this paper, we present a two-sector model, which seems to be the approach adopted in the most recent literature, as well as a three-sector model, more in keeping with the older Dutch disease literature.

According to Davidson and Matusz (2011), the empirical evidence on how trade affects the unemployment rate is virtually non-existent. In addition, what little empirical research does exist has contradictory findings. This paper aims to at least partially address this deficiency. Our empirical contribution is to estimate the effect of trade on unemployment using both reduced form and structural approaches. We use data for Australia for the period 1960-2008. The estimates provide strong evidence that rising demand for exports and higher terms of trade reduce the unemployment rate. Capital accumulation in tradeable goods industries also reduces unemployment. The other major factor found to worsen unemployment is the level of unemployment benefits. In the next section, we outline the theory. Section 3 discusses the data, the econometric methodology and presents the model estimates. The last section concludes.

\section{Theory of an economy with a booming export sector}

2.1. The basic two-sector model. Assume that there are two-sectors, $X$ and $Y$. The factors of production are labour and capital, $L$ and $K . X$ is assumed to be the export sector and $Y$ is the import-competing sector. We assume that there are a large number of firms in both sectors of the economy and that bargaining takes place with firm-level unions. Nevertheless, workers are free to move between the sectors. On the other hand, capital is assumed to be sector-specific, we denote this fact by using an overscore, i.e., $\bar{K}_{X}$ and $\bar{K}_{Y}$.

The production function of a firm in sector $X$ is $x=x\left(k_{x}, l_{x}\right)$ and for a sector $Y$ firm is $y=y\left(k_{y}, l_{y}\right)$. All firms are profit maximisers, with profit for a representative firm in each sector given by

$$
\pi_{x}=p x-w l_{x}-r_{x} k_{x} \text { and } \pi_{y}=y-w l_{y}-r_{y} k_{y},
$$

where $w$ is the wage and $r$ is the price of capital. Note that good $Y$ is the numeraire and that the price of good $Y$ is normalised to one; hereafter $p$ is referred to as the terms of trade.

We consider an industry in which there is no strategic interaction between firms. Another critical assumption is that the industry market structure generates rents that are shared 
between firms and unions. In the following, we consider the case of a representative firm in sector $X$ which bargains with a firm-level union over wage-employment contracts. If bargaining is efficient, the choice from the set of efficient contracts is the one that maximises the Nash product, i.e., ${ }^{2}$

$$
S(w, l)=(\pi(w, l ; p))^{1-\varphi}(U(w, l)-\bar{U})^{\varphi},
$$

where $U($.$) is the union's utility function and \bar{U}$ denotes the disagreement point for the union. (The subscript on $l$ is dropped). The parameter $\varphi \in(0,1)$ indexes collective bargaining strength.

We assume that the solution lies in the interior of the choice set and that $S$ is strictly concave so that the solution is unique and may be characterised by the first-order conditions. Suppressing arguments and using subscripts to denote partial derivatives, the equation for the contract curve, which equates the slope of the union's indifference curve and the firm's iso-profit curve is

$$
-\frac{U_{l}}{U_{w}}=-\frac{\pi_{l}}{\pi_{w}}
$$

Further headway is made by investigating the implications of some commonly considered functional forms for union preferences. Consider the popular specification used by McDonald and Solow (1981). Here the union comprises $m$ homogeneous workers, each endowed with one unit of labour time. Prior to actual wage and employment negotiations, a worker's expected utility is given by

$$
E U=U(w)+(U(\omega)-U(w)) \max \left\{0, \frac{m-l}{m}\right\},
$$

where $U($.$) is increasing and concave, w$ is the wage rate if employed and the reservation alternative is denoted by $\omega$, i.e., the union's disagreement payoff is $\bar{U}=U(\omega)$.

An obvious implication of equation (4) is that if all union members are employed (i.e., $l \geq m$ ), then a union representing inside workers becomes completely 'wage-oriented' when it negotiates with the firm. Specifically, unlike the case in which $m$ is so high that all workers have a probability of being unemployed equal to $(m-l) / m$, when $m$ is low so that all union members are employed, the union is completely wage-oriented and maximises $m U(w)$. We consider this particular case in part A of the Appendix.

When $l<m$, equation (3) yields

$$
\frac{U(w)-U(\omega)}{U_{w}}=-\pi_{l} .
$$

Since $U(\omega) \cong U(w)+(\omega-w) U_{w}(w)$, then $p x_{l}=\omega$ and labour is hired until its marginal revenue product equals the reservation wage. It is straightforward to show that the negotiated wage equals

\footnotetext{
2 It is debatable whether firms and unions negotiate both wages and employment or just wages alone. Empirical evidence in favour of efficient bargaining is mixed (Farber, 1986, p.1067). On the other hand, negotiation over work rules may ensure that bargains are efficient.
} 


$$
w=\omega+\frac{\varphi}{(1-\varphi)} \frac{\pi}{l}
$$

Further, $w_{\omega}>0, l_{\omega}<0, \pi_{\omega}<0$ and $U_{\omega}>0$. The impact of higher reservation wages shifts the threat point in the union's favour, raising their welfare and lowering the firm's. Equation (6) can be rewritten as

$$
w=\left(1+\frac{\varphi(1-\eta)}{\eta}\right) \omega,
$$

where $\eta=l \tilde{\pi}_{l} / \tilde{\pi}>0$ is the elasticity of 'net profit'. ${ }^{3}$ Most importantly, the negotiated wage is higher than the reservation wage. In fact, regardless of whether bargaining is efficient, or whether unions negotiate over wages alone, the wage is simply a multiple of the reservation wage. ${ }^{4}$ That is,

$$
w=\lambda \omega, \lambda>1 \text {. }
$$

The crucial issue is what determines the reservation wage. Blanchflower et al. (1996, p.243) argue that it can be thought of as a function: $\omega=\omega\left(w_{0}, B, u\right)$, where $w_{0}$ is the going wage in the other sector(s) of the economy, $B \quad\left(<w_{0}\right)$ is the level of income when unemployed (e.g., publicly-provided unemployment benefits) and $u$ is the unemployment rate of the type of worker employed by the firm. According to Nickell and Layard (1999, pp.3048-9), a reasonable case to consider is

$$
\omega=u B+(1-u) w .
$$

That is, the reservation wage depends on the wage that can be earned at other firms and the unemployment benefit. These amounts are weighted by the probability of remaining unemployed and the probability of finding another job. Without any worker heterogeneity, these are the economy-wide probabilities of unemployment and employment, respectively. Note that the rate of unemployment is $u=(\bar{L}-L) / \bar{L}$, with $\bar{L}$ the total supply of labour and $L$ the total demand for labour in sectors $X$ and $Y$.

2.2. The wage-setting curve. At a micro level, $u$ is regarded as exogenous by the worker (and his union). Given that firms within each sector are identical and that every firm-specific union has the same objective function, the equilibrium of this economy entails $w_{x}=w_{y}=w$. Therefore, in equilibrium, the aggregate wage-setting curve (WSC) of the economy is obtained by combining (8) and (9), i.e.,

${ }^{3}$ Combining the first-order conditions yields: $w-\varphi(\tilde{\pi} / l)-(1-\varphi) \omega=0$, where $\tilde{\pi}=\pi+w l$. Defining $\eta=l \tilde{\pi}_{l} / \tilde{\pi}$ and noting that $\tilde{\pi}_{l}=\omega$ yields equation (7). Second-order conditions require $\eta<1$.

${ }_{4}^{4}$ This is not a particularly novel insight, e.g., see McDonald (2002); see also part A of the Appendix. In addition, this characteristic is not peculiar to bargaining models. For example, in efficiency wage models firms pay workers a wage above the reservation wage in order to reduce turnover costs or to motivate worker effort (see Blanchard and Katz, 1997). In matching models, the wage is also determined by bilateral Nash bargaining and splitting the total surplus from a job match. Specifically, workers receive a wage over and above the asset value of being unemployed (Mortensen and Pissarides, 1994). 


$$
w=\frac{B}{1-\frac{\theta}{u}},
$$

where $\theta=1-\lambda^{-1} \in(0,1)$. Equation (10) implies that the wage and the unemployment rate are inversely related and that the wage and total labour demand are positively related. In effect, the WSC replaces the perfectly inelastic labour supply schedule; an increase in labour demand leads to higher wages and employment, with a fall in the equilibrium rate of unemployment. ${ }^{5}$

2.3. The equilibrium unemployment rate. The aggregate labour demand curve is derived as the horizontal summation of the sectoral labour demand curves. The equilibrium wage, labour demand and unemployment are determined by the interaction of the WSC and aggregate labour demand. The relevant results are collected in the following Proposition.

\section{Proposition 1 (two-sector model)}

a) $u=u\left(p, \bar{K}_{X}, \bar{K}_{Y}, \bar{L}, B, \lambda\right)$;

b) Unemployment falls with improved terms of trade, $u_{p}<0$;

c) Unemployment falls with greater capital accumulation in either sector, i.e., $u_{\bar{K}_{X}}<0$ and $u_{\bar{K}_{Y}}<0$;

d) Unemployment rises with a greater labour supply, $u_{\bar{L}}>0$;

e) Unemployment rises in the unemployment benefit and union bargaining power, i.e., $u_{B}>0$ and $u_{\lambda}>0$.

Proof: See part B of the Appendix.

As long as we are willing to countenance the WSC construct, none of these results seem particularly surprising. ${ }^{6}$ The main result from our viewpoint is that higher terms of trade reduce unemployment. We now turn to the three-sector model in order to see whether this or any of the other key results are affected when a non-tradeables or services sector is explicitly introduced.

2.4. The three-sector model and Dutch disease. There is a large literature studying the effects of a booming sector on the rest of the domestic economy. A traditional concern has been the possibility of deindustrialisation, whereby a booming sector draws factors from a lagging sector. This phenomenon for some countries is referred to as the "resource curse" (e.g., Mehlum et al., 2006), but is more generally referred to as "Dutch disease" (see Cordon and Neary, 1982 and Cordon, 1984). For obvious reasons, the phenomenon has been long-studied in Australia (e.g., Gregory, 1976 and Snape, 1977). Within Australian policy circles there is a

\footnotetext{
${ }^{5}$ It is worth noting that if the unemployment benefit replacement rate, $b=B / w$, were an immutable constant fixed by policy, then the unemployment rate is also constant, i.e., $u=\theta(1-b)^{-1}$. However, in most countries, the level of $B$ is capped, so that $b^{\prime}(w)<0$ for some critical wage level. The condition that $b^{\prime}(w)<0$ is sufficient to guarantee that wages and unemployment are inversely related.

${ }^{6}$ Blanchflower and Oswald (1995) find strong evidence of a wage curve for twelve countries, including Australia. The authors conclude that the hypothesis of an elasticity of wages with respect to unemployment of -0.1 cannot be rejected.
} 
concern expressed about a "two speed economy", with a rapidly advancing sector (mining) and another sector under severe competitive pressure from import competition (manufacturing). While surging raw materials prices are an undoubted windfall for Australia, the dependence on low value-added products and the non-diversification of the economy's industrial structure are viewed as potentially problematic.

The extension of the model to three sectors is relatively straightforward. ${ }^{7}$ Assume that there are three sectors $-X, Y$ and $N$ - respectively, the export, import-competing and nontradeables sectors. Once again, the tradeable goods sectors face given world prices. The economy still has the same Ricardo-Viner structure, as above. First, under the assumption that labour is mobile across all sectors, the WSC is trivially the same. Secondly, the labour demand side of the economy is readily extended to encompass three sectors rather than two.

The primary concern of the Dutch disease literature is the extent to which a booming sector drains the lagging sector. The issue is somewhat complicated by the presence of a nontradeables sector. Cordon and Neary (1982) note that an improvement in the terms of trade has two effects: a resource movement effect as well as a spending effect. The former effect is the usual reallocation of labour along the economy's transformation frontier. As the price of sector $X$ output rises, this draws labour out of sectors $Y$ and $N$. The latter effect arises because higher terms of trade raise real income. This effect raises the demand for nontradeables. The price of $N$ relative to tradeable goods rises and this draws labour out of $X$ and $Y$. Regardless of the impact on the non-tradeables sector, the importables sector shrinks. As mentioned, this deindustrialisation has been the focus of the literature; although as Cordon (1984, p.363) notes, in the case of Australia this could equally mean 'de-agriculturalisation'.

The comparative static results for unemployment arising from the extension of the model to three sectors are given in Proposition 2. The equilibrium wage, labour demand and unemployment are still given by the intersection of the WSC and aggregate labour demand. The main 'novelty' is that the price of non-tradeables is endogenous.

\section{Proposition 2 (three-sector model)}

a) $u=u\left(p, \bar{K}_{X}, \bar{K}_{Y}, \bar{K}_{N}, \bar{L}, B, \lambda\right)$ and $p_{n}=p_{n}\left(p, \bar{K}_{X}, \bar{K}_{Y}, \bar{K}_{N}, B, \lambda\right)$, where $p=p_{X} / p_{Y}$ and $p_{n}=p_{N} / p_{Y}$;

b) Unemployment falls with improved terms-of-trade, $u_{p}<0$;

c) Unemployment may rises with a greater labour supply, higher unemployment benefits or union bargaining power., i.e., $u_{\bar{L}}>0, u_{B}>0$ and $u_{\lambda}>0$;

\footnotetext{
7 What is far from straightforward is deciding which industries belong to which sector. For example, Australia both exports and imports automobiles. Rather than export and import-competing sectors, Cordon (1984) refers to booming and lagging sectors. But, obviously this classification has problems of its own with the lagging sector producing both non-boom exportables as well as importable goods. In addition, some outputs are both inputs as well as final goods. Finally, to the extent that imported goods are not perfect substitutes for domestically-produced import-competing goods, then importables have a non-tradeable goods component (and therefore may benefit from a boom). We ignore these issues, but attempt to address these categorisation issues in the empirical work.
} 
d) Unemployment falls with greater capital accumulation in either of the tradeable goods sectors, i.e., $u_{\bar{K}_{i}}<0, i=X, Y$;

e) Unemployment may rise or fall with greater capital accumulation in the non-tradeables sector.

Proof: See part C of the Appendix.

Once again, improvements in the terms of trade lower the equilibrium unemployment rate. Increases in either export prices or the capital stock in the tradeable goods industries result in higher total employment in the economy, i.e., the equilibrium rate of unemployment is lower. Given a positively-sloped WSC, an increase in aggregate labour demand, not only causes the equilibrium wage rate to be higher, but more importantly, the equilibrium unemployment rate to be lower. Interestingly, an increase in the capital stock in the non-tradeables sector does not necessarily reduce unemployment. The expansion of employment in the non-tradeables sector comes at the expense of employment in the tradeable goods sectors.

2.5. Other considerations. In this sub-section, we briefly consider two issues related to the above discussion. First, we discuss the relationship between the Phillips curve literature and the model presented here. Secondly, we consider the longer-term implications of the model, in particular, the consequences of weakening the capital-specificity assumption.

2.5.1. Relation to the Phillips curve literature. The empirical literature on the Phillips curve is enormous. Estimation normally involves regressing, with varying degrees of statistical sophistication, a measure of wage or price inflation on the unemployment rate. The overall focus of the studies has essentially been two-fold. Foremost has been to determine whether there is any evidence of a unique equilibrium rate of unemployment or whether unemployment displays evidence of hysteresis, i.e., whether (or not) demand-side influences, such as government spending, can affect the unemployment rate more than temporarily. Secondly, has been to ascertain whether supply-side and institutional factors, such as unemployment benefits or the benefit replacement rate, affect the equilibrium unemployment rate.

To our knowledge, there are no empirical studies of the effects of the terms of trade on unemployment. ${ }^{8}$ While the concern in the present paper is not with the Phillips curve per se, it is related. Interestingly, in Australia the steady decline in the rate of unemployment rate in the past decade or so has coincided with a period of relatively steady rates of price inflation. The latter development has largely been the result of the Reserve Bank of Australia keeping inflation within its fairly tight two to three per cent target range for inflation. Taken by itself, this suggests that a Phillips curve with a constant natural rate does not exist. This provides further justification for the model developed in this paper.

2.5.2. The long-run and capital mobility. In our model, improved terms of trade increase labour demand, raise the nominal wage and lower unemployment. In the Heckscher-Ohlin model, changes in the terms of trade only affect factor prices. In the model here, there is unemployed labour. Hence, higher export prices affect unemployment and the returns to factors in the long-run. ${ }^{8}$ Nickell et al. (2005) find that higher real import prices raise unemployment in a panel study of
OECD countries. The authors do not study the impact of export prices. 
Regardless of the bargaining protocol considered, capital owners are the residual claimants. Higher terms of trade increase the return to capital owners in sector $X$ and lower the return to capital in sector $Y$. In the long-run, capital flows from sector $Y$ to sector $X$. Therefore, there is a secondary or indirect impact on unemployment due to higher export prices. The movement of capital serves to boost the marginal productivity of labour in sector $X$ even further, while the marginal productivity of sector $Y$ labour falls. The demand for labour rises in sector $X$ and falls in sector $Y$. The impact on total labour demand of this movement in capital in the long-run is therefore indeterminate and depends among other things on the elasticity of labour demand and the factor intensities in the two sectors. ${ }^{9}$

Moreover, in the case of international capital mobility, capital flows into the export sector in response to the higher real return on capital. According to the Rybczynski theorem, the output of the relatively capital-intensive sector (in Australia's case, sector X) increases even more, but the output of the labour-intensive manufacturing sector falls even further. However, the impact on wages and on unemployment, of this effect is also unknown. At this juncture, it seems appropriate to turn to the empirical work.

\section{Econometric methodology and results}

3.1. Data description. Our focus in this section is on the examining the determinants of the long-run rate of unemployment, as suggested by the three-sector model. All estimation is carried out using annual data for Australia for the period from 1960 to 2008. The data sources are described in detail in Appendix table A1 and the descriptive statistics appear in table 1. All data are publicly available. The choice of variables is motivated by the theory described in the previous section. As for the definitions of the sectoral capital stocks, $K_{X}$ is mining, $K_{Y}$ is manufacturing plus agriculture and $K_{N}$ is the capital stock for all other sectors; this roughly accords with Cordon's (1984) booming versus lagging sector categories.

Alternatively, we also define $K_{X}$ as mining plus agriculture, $K_{Y}$ for manufacturing and $K_{N}$ for the capital stock in all other sectors, which accords with a more 'usual' export versus import sector distinction.

\section{- Table 1 here -}

Immediately apparent is the enormous expansion of the mining sector in the last half century; the investment and subsequent growth of the capital stock easily dwarfs the growth in all other sectors of the economy. A visual impression of some of the other key data is given in figure 1. The terms of trade, ToT, measured as the ratio of the implicit price deflator of exports of goods and services to the implicit price deflator of imports of goods and services, captures the dependence on overseas economic developments and the economic dimension of growing integration with countries such as China. While industrial country protectionists fret about China's impact on the world prices of manufactures, even more pronounced is China's impact on the price of energy and resources. For countries, like Australia, the

\footnotetext{
9 Matusz (1985) shows that while the factor price equalisation theorem and the Rybczynski theorem both hold in a Heckscher-Ohlin model with implicit contracts and unemployment, that the Stolper-Samuelson theorem is weakened. Of course, this is further complicated by international immigration which is stimulated by higher wages. Cordon (1984) shows that immigration increases spending on both non-tradeables and importables, although not by enough to reverse de-industrialisation.
} 
consequence is extraordinarily high terms of trade. The rising terms of trade are predicted to result in a movement of labour from manufacturing to primary industries.

- Figure 1 here -

We use Union as our proxy for union bargaining power, $\lambda$, and $B R R$ as our measure of unemployment benefits generosity. There has been an enormous surge in the terms of trade since the year 2000 and this period also coincided with falling unionisation. However, unionisation peaked at nearly one half of the labour force in 1963 and has fallen since; deunionisation accelerated after 1986. In addition, the unemployment benefit replacement ratio, after peaking in 1993, has been steadily declining. Coincidentally perhaps, 1993 has the highest unemployment rate in our data set; the unemployment rate (denoted as UR) has fallen almost every year since that date. There is an obvious up-tick in the unemployment rate just prior to the onset of the GFC in 2008. We also include Inflation in order to examine the presence of a Phillips curve relationship and to gauge the robustness of estimates of the baseline model specification.

We now turn to the econometric estimates of the models of unemployment described in section 2 .

3.2. Unit roots. It is well known that the data generating process for most macroeconomic time series are characterised by unit roots, which rules out the use of standard econometric methods. Therefore, it is important to analyse the time series properties of the data in order to avoid spurious results generated by unbounded variances of parameter estimates due to the presence of unit roots. The three most commonly used unit root tests are applied here, i.e., the Augmented Dickey-Fuller (ADF), Phillips-Perron (PP) and Kwiatkowski-PhillipsSchmidt-Shin (KPSS) unit root tests, on the relevant variables in order to ensure the robustness of the test results. What distinguishes the tests is that the null hypothesis for the $\mathrm{ADF}$ and PP is the alternative hypothesis for the KPSS. That is, while the former (ADF and PP) are derived under the null hypothesis of unit roots the latter (KPSS) is obtained under the stationary null hypothesis. The results reported in table 2 show that all variables except Inflation are non-stationary at the five per cent level of significance. The non-rejection of the unit root hypothesis leads to testing for the second unit root, i.e., a unit root in first differences. The test results in first differences are also reported in table 2 . The results indicate that Inflation is $\mathrm{I}(0)$ and all the other series are $\mathrm{I}(1)$. The results based on the stationary alternative (ADF and PP) and non-stationary alternative (KPSS) in our exercise ensure that the results are robust and are unaffected by the weak power of standard unit root test procedures.

- Table 2 here -

3.3. Co-integration: In order to examine the existence of a long-run relationship between the variables in the theory discussed in section 2, we test for co-integration among them. For the three-sector model, recall that $u=u\left(p, p_{n}, \bar{K}_{X}, \bar{K}_{Y}, \bar{K}_{N}, \bar{L}_{,} B, \lambda\right)$, we test for co-integration between the variables in $z_{t}=\left(U R_{t}, \ln K_{X, t}, \ln K_{Y, t}, \ln K_{N, t}, T o T_{t}, P_{N, t} / P_{Y, t}, B R R_{t}, \ln L F_{t}\right.$, Union $_{t}$, Inflation $\left._{t}\right)$.

Since all the variables (other than Inflation) are non-stationary, the linear combination of one or more of these series may have a long-run relationship. The multivariate co-integration test based on the Johansen and Juselius (1990) method is used to test for these relationships. 
Accordingly, we estimate the following $n$-variate, $p^{\text {th }}$-order Gaussian vector autoregression (VAR) process

$$
z_{t}=\mu+\sum_{i=1}^{p} \Pi_{i} z_{t-i}+\Psi D_{t}+\varepsilon_{t}, t=1,2, \ldots, T,
$$

where $\mu$ is a vector of constants, $D_{t}$ is an intercept dummy and $\varepsilon_{t}$ is a normally and independently distributed $n$-dimensional vector of innovations with zero mean and non-singular covariance matrix. The optimal lag length $p(=2)$ is determined by the Schwartz criterion. As noted above, we consider different specifications for $z_{t}$ to examine the robustness of our results.

Since each component of $z_{t}$ (except Inflation) is I(1), we rewrite equation (11) in vector error correction (VEC) form

$$
v_{t}=\mu+\Gamma_{1} v_{t-1}+\Pi z_{t-1}+\Psi D_{t}+\varepsilon_{t},
$$

where $v_{t}=\left(\Delta U R_{t}, \Delta \ln K_{X, t}, \Delta \ln K_{Y, t}, \Delta \ln K_{N, t}, \Delta T o T_{t}, \Delta\left(P_{N, t} / P_{Y, t}\right), \Delta B R R_{t}, \Delta \ln L F_{t}, \Delta\right.$ Union $_{t}$, Inflation $\left._{t}\right)$. In addition, $\Gamma_{1}=-\Pi_{2}$ and $\Pi=\Pi_{1}+\Pi_{2}-I$. The long-run $n \times n$ matrix $\Pi=\alpha \beta^{\prime}$ determines how many independent linear combinations of the elements of $z_{t}$ are stationary. Here $\alpha$ and $\beta$ are $n \times r$ matrices with rank $r(0<r<n)$. The rank of $\Pi$ gives the number of independent co-integrating vectors and can be formally tested using the trace test and the maximum eigen value test.

The trace statistic tests the null hypothesis that $H_{o}: r=q$ against the alternative that $r>q$ and is given by

$$
\lambda_{\text {trace }}(q)=-T \sum_{i=q+1}^{n} \ln \left(1-\lambda_{i}\right)
$$

where the $\lambda_{i}$ 's are the eigen values of $\Pi$, such that $\lambda_{1}>\lambda_{2}>\ldots>\lambda_{n}$. The $\lambda_{\text {trace }}$ statistic sequentially tests the null hypothesis that the number of co-integrating vectors is at most $q$ against the alternative that the number of co-integrating vectors is more than $q$, where $q=1,2, \ldots, n$.

The maximum eigen value statistic tests the null hypothesis that $H_{o}: r=q$ against the alternative that $r=q+1$ and is given by

$$
\lambda_{\max }(q)=\lambda_{\text {trace }}(q)-\lambda_{\text {trace }}(q+1) .
$$

The $\lambda_{\max }$ statistic tests the null hypothesis that the number of co-integrating vectors is equal to $q$ against the alternative that the number of co-integrating vectors is $q+1$.

The results of the trace test and the maximum eigen value test are reported in table $3 .{ }^{10}$ The results based on the Johansen-Juselius procedure for the models with Inflation indicate that the null of $r=0$ (i.e., no co-integrating relationship) and $r=1$ (i.e., one co-integrating relationship) are rejected at the five per cent level of significance. The sequential testing fails to reject the null hypothesis that the number of co-integrating vectors is at most two at the five per cent level of significance. This indicates that the stationary variable Inflation alone

10 The critical values for both the trace and the maximum eigen value test statistics are obtained through Monte Carlo simulations with 10,000 replications. 
forms a trivial co-integrating vector while all the other variables form another co-integrating vector. On the other hand, for the models without Inflation the null of $r=0$ (i.e., no co-integrating relationship) is rejected at the five per cent level of significance. Sequential testing fails to reject the null hypothesis that the number of co-integrating vectors is at most one at the five per cent level of significance. The results strongly suggest the existence of a long-run relationship between the variables of interest.

- Table 3 here -

3.4.1. The reduced form model: The following vector error correction (VEC) model is estimated to establish the long-run and short-run relationships between the variables.

$$
v_{t}=\mu+\alpha_{1} e_{1, t-1}+\alpha_{2} e_{2, t-1}+\Gamma v_{1, t-1}+\Psi D_{t}+\varepsilon_{t},
$$

where $v_{t}=\left(\Delta U R_{t}, \Delta T o T_{t}, \Delta\left(P_{N, t} / P_{Y, t}\right), \Delta K_{X, t}, \Delta K_{Y, t}, \Delta K_{N, t}, \Delta\right.$ Union $_{t}, \Delta B R R_{t}, \Delta \ln$ LF $_{t}$, Inflation $)$ and $v_{1, t-1}=\left(\Delta U R_{t-1}, \Delta T o T_{t-1}, \Delta\left(P_{N, t-1} / P_{Y, t-1}\right), \Delta K_{X, t-1}, \Delta K_{Y, t-1}, \Delta K_{N, t-1}, \Delta\right.$ Union $_{t-1}, \Delta B R R_{t-1}$, $\left.\Delta \ln L F_{t-1}\right)$ are vectors of endogenous and lagged endogenous variables, respectively. Furthermore, $e_{1 t}=U R_{t}-\beta_{2} T_{0} T_{t}-\beta_{3}\left(P_{N, t} / P_{Y, t}\right)-\beta_{4} \ln K_{X, t}-\beta_{5} \ln K_{Y, t}-\beta_{6} \ln K_{N, t}-\beta_{7}$ Union $_{t}$ $-\beta_{8} B R R_{t}-\beta_{9} \ln L F_{t}-\beta_{10}$ Left $_{t}$ and $e_{2 t}=$ Inflation $_{t}$ are the error processes from the longrun static equation. ${ }^{11}$ Left is a dummy variable equal to one if there is a Labor government at time $t$, and zero otherwise. $\alpha_{i j}$ denotes the speed of adjustment parameter for the $i^{\text {th }}$ co-integrating vector and the $j^{\text {th }}$ equation, i.e., it explains the speed at which the process approaches the long-run through the $j^{\text {th }}$ equation. The models without Inflation have only one error correction term, $e_{1 t}$. The 10x9 matrix $\Gamma$ captures the short-run dynamic relationship between the variables of interest and $\Psi$ is a $10 \times 1$ vector of parameters corresponding to the intercept dummies. CUSUM tests are used to examine the validity of other structural changes in the model in addition to the Left dummy. The results show the absence of structural breaks other than for Left. ${ }^{12}$

The long-run relationship between $U R$ and the other variables is established through the statistical significance of the $\beta$ coefficients along with the statistical significance of $\alpha_{11}$. For example, the effect of ToT on $U R$ is established through the statistical significance of $\beta_{2}$. In order to establish the genuine long-run causal relationship from any variable to $U R$ requires the speed of adjustment $\alpha_{11}$ to be negative in the $\Delta U R$ equation. On the other hand, the short-run relationship between the variables is established through the components $\gamma$ of $\Gamma$. Since our concern is with the determinants of the unemployment rate, we only report the results for the UR equation. ${ }^{13}$

3.4.2. The reduced form results. The results are reported in table 4 . We find that the parameters representing the short-run dynamic effects, other than the own lag and the error correction terms, are statistically insignificant (even at the ten per cent level). Hence, we present the

11 The long-run relationship, or static equation, is represented by a contemporaneous relationship between the variables of interest rather than a relationship with lags.

${ }^{12}$ For the sake of brevity, we do not present the results. They can be obtained from the authors by request.

${ }^{13}$ The complete set of results is available from the authors by request. 
results for the $\beta$ s (i.e., the long-run relationships), error correction terms, $\alpha_{11}$ and $\alpha_{21}$, and the coefficient corresponding to $\Delta U R_{t-1}$.

\section{- Table 4 here -}

The results show that the variables of interest affect the unemployment rate in the long-run, but not in the short-run. It is possible that a failure to find any short-run relationship from any of the variables to unemployment could be due to an aggregation problem. Marcellino (1999) and Rajaguru and Abeysinghe (2008) also show that temporally aggregated data (e.g., such as those involving annual frequencies) in a co-integrated system may lead to misleading short-run causal information between the variables. In particular, the short-run information disappears due to temporal aggregation and any information is funnelled through the long-run contemporaneous relationship between the variables. In turn, this may create misleading long-run relationships between the variables. However, Rajaguru and Abeysinghe (2008) show that the genuine long-run causal relationship between the variables can be established, even with highly aggregated data, when the error correction term appears with the correct sign; in our case, negative for the unemployment rate equation. We find negative and significant estimates for the error correction term in the unemployment rate equation. Hence, the long-run results are unaffected by any spurious causal relationship arising from temporally aggregated or systematically sampled data.

In table 4, the baseline model suggested by the theory appears in column (1). Column (2) contains the results from the same model which is re-estimated by including Inflation. We make this inclusion in order to examine the robustness of the baseline specification in the previous column. The estimates using the alternative capital stock classification is reported in column (3). In column (4), we present the results of re-estimating the models when the log of the labour force $(L L F)$ is excluded. This exclusion is made due to a concern that this variable could be spuriously related to the denominator of the unemployment rate and could therefore be affecting the results. Finally, in column (5) we use the disaggregated price series (i.e., by replacing ToT with the separate prices of exports and imports in the regression model). ${ }^{14}$ The multivariate normality test shows that the errors are normally distributed at a five per cent level of significance. In addition, there is no statistically significant evidence of any autocorrelation, at either one or two lags.

To understand the specifics of what the results show, consider the baseline specification reported in column (1) of table 4 . Presented here are the estimates of equation (15), i.e., the relationship between the unemployment rate, the (natural logarithm of) the labour force and capital stock in sectors $X$ and $Y$. It also includes the terms of trade, ToT, and our proxy for $\lambda$, Union, as well as the unemployment benefit replacement ratio, $B R R$. What the results indicate is that the terms of trade are very important. A ten per cent improvement in ToT reduces the unemployment rate by just over one full percentage point (i.e., $\left.-0.15^{*} 6.94\right)$. This is

\footnotetext{
14 In addition, we estimate equation (15) for a variety of other models to examine the sensitivity of our results. Once again, we include and then exclude inflation, use two different capital stock classifications and include and exclude the labour force variable. Also, we run a variety of regression specifications in which prices are strictly relative prices and others in which prices are left unrestricted. These results are in a separate Appendix available from the authors upon request.
} 
obviously a large effect. ${ }^{15}$ The other key, and highly statistically significant, variable is $B R R$. In this case, a ten per cent increase over the most recent value of the $B R R$ raises the unemployment rate by just over 0.7 percentage points (i.e., $0.36^{*} 2.02$ ). The effect of unionisation is significant but economically smaller; a further ten per cent fall in the most recent value of the Union would lower the unemployment rate by less than 0.06 percentage point (i.e., $0.03^{*} 1.89$ ). The other statistically significant variables have generally unsurprising and expected signs. ${ }^{16}$ The positive sign on the political dummy reveals that the Labor government has presided during periods of higher unemployment.

An interesting feature of the results is that capital accumulation in the tradeable goods sector is, as predicted by the three-sector model, far more important than capital accumulation in the non-tradeable goods sector for lowering the rate of unemployment. In other words, capital accumulation in the services sector (which includes the government sector) is not particularly useful in lowering unemployment. As for the labour force, the immigration intake due to the mining boom soared. Together with the native-born increase, the growth in the labour force has been about two per cent annually since the year 2000. We find that this growth has lowered the unemployment rate by just less than 0.6 percentage points (i.e., $-29.81 * 0.02)$.

In column (2) we further control for the inflation rate in order to allow for a potential Phillips curve trade-off relationship. If there is in fact such a relationship, the estimated coefficient of Inflation "should" be negative. The coefficient is negative, but statistically insignificant, i.e., there is no evidence that inflation lowers unemployment. As mentioned, given the targeting of the inflation rate within a narrow band by the Reserve Bank of Australia and the large falls in the unemployment rate in the last decade and a half, this result was expected. Column (3) contains estimates of the baseline model, with an alternative definition of the capital stock for sectors $X$ and $Y$. Once again, the results are robust. The result for ToT is somewhat smaller, that for $B R R$ is identical and that for the labour force is still negative, but statistically insignificant. Likewise, in column (4) the results are clearly not driven by any lock-step correlation between the log of the labour force and the denominator of the unemployment rate statistic. ${ }^{17}$ Finally, the results using the unrestricted prices in column (5) are extremely interesting. The ToT result is driven by driven by both falling prices of imports and rising

15 While this particular estimate may seem 'large', it should be noted that Felbermayr et al. (2009) show a ten per cent increase in total trade openness reduces long-run unemployment by about one percentage point for a large panel of countries.

16 The standardised beta coefficients for the significant variables are: ToT -0.49; LK_mining -0.32; LK_manuf_agr -0.44; Union 0.11; BRR 0.53; and LLF -0.30.

17 We also estimated VEC models for labour force participation (LFP). One possible caveat concerning the "good news" about a falling unemployment rate is that this may conceal the fact that LFP is also falling. For example, while lower unemployment benefits may lower the unemployment rate, they may also encourage labour force withdrawal and a lower LFP. In fact, LFP tracked steadily upwards from 1993 (a recession year) until 2008. With LFP defined as the number of workers in the labour force (i.e., either employed or unemployed) divided by the number of persons aged between 16 and 65 years, it was 65.8 per cent in 1960 (it's lowest value), 72.9 per cent in 1993 and 77.8 per cent in 2008 (it's highest value). The VEC results reveal that the effects of ToT are positive (albeit only significant in one model specification) and $B R R$ is negative, but always statistically insignificant. The set of results for LFP are available from the authors upon request. 
prices for exports. However, the magnitude of the rise in export prices needs to be borne in mind. From 2000 to 2008, import prices fell by 5.1 per cent, while export prices rose 49.1 per cent. Over this period then, this suggests that the terms of trade effect reduced the rate of unemployment by 0.6 percentage points (i.e., $\left.\left(0.01^{*} 49.1\right)+(0.02 * 5.1)\right)$. With China now being Australia's number one export market and its second ranked source of imports, it is tempting to conclude that this effect captures the "China effect" on the rate of unemployment.

3.5.1. The structural model: The following empirical approach addresses the theoretical model developed in section 2 more explicitly. In particular, the intersection of the WSC (i.e., equation (10)) and the aggregate labour demand schedule determines the equilibrium unemployment rate. We estimate the following model (derived as equations (A16) and (A23) in part $C$ of the Appendix),

$$
\begin{aligned}
& \Delta U R_{t}=\kappa_{B} \Delta B_{t}+\kappa_{p} \Delta p_{t}+\kappa_{\lambda} \Delta \lambda_{t}+\kappa_{\bar{L}} \Delta \ln \bar{L}_{t}+\kappa_{\bar{K}_{X}} \Delta \bar{K}_{X, t}+\kappa_{\bar{K}_{Y}} \Delta \bar{K}_{Y, t}+\kappa_{\bar{K}_{N}} \Delta \bar{K}_{N, t}+\kappa_{p_{n}} \Delta p_{n, t} \\
& \Delta p_{n, t}=\tau_{B} \Delta B_{t}+\tau_{p} \Delta p_{t}+\tau_{\lambda} \Delta \lambda_{t}+\tau_{\bar{K}_{X}} \Delta \bar{K}_{X, t}+\tau_{\bar{K}_{Y}} \Delta \bar{K}_{Y, t}+\tau_{\bar{K}_{N}} \Delta \bar{K}_{N, t}+\tau_{u} \Delta U R_{t} .
\end{aligned}
$$

As we show in part D of the Appendix, many of the coefficients (the $\kappa_{i}$ and $\tau_{i}$ ) are related to one another, i.e., there are cross-coefficient restrictions. For example, $\kappa_{B}=\delta_{2} A_{B} / \delta_{1}$ and $\kappa_{p}=G_{1} B A_{B} / p \delta_{1}$, where $\delta_{1}=\left(1-A_{L} \delta_{2}\right) \bar{L}$ and $\delta_{2}=\left(G_{1}+p H_{1}+p J_{1} / p_{n}\right)$ are each functions of $A_{B}$ and $A_{L}$. The expressions are directly estimated using data, i.e., $A_{B}=$ $(\bar{L}-L) /(\bar{L}-\lambda L) p$ and $A_{L}=(\lambda-1) \bar{L} B A_{B} /(\bar{L}-L)(\bar{L}-\lambda L)$. (Note that aggregate labour demand is the sum of the labour demand in each sector, i.e., $L\left(w, \bar{K}_{X}, \bar{K}_{Y}\right)=G\left(w, \bar{K}_{X}\right)+H\left(w, \bar{K}_{Y}\right)$ $+J\left(w, \bar{K}_{N}\right)$, where $G_{1}<0, G_{2}>0, H_{1}<0, H_{2}>0, J_{1}<0$ and $\left.J_{2}>0\right)$. A similar approach is adopted to estimate the remaining parameters.

While $A_{B}$ can be directly estimated using the data, some of the other components are functions of labour and capital in the respective sectors, i.e., $X=X\left(L_{X}, \bar{K}_{X}\right), Y=Y\left(L_{Y}, \bar{K}_{Y}\right)$ and $N=N\left(L_{N}, \bar{K}_{N}\right) . X_{1}, X_{2}, Y_{1}, Y_{2}, N_{1}$ and $N_{2}$ are the derivatives with respect to the first and second elements of $X, Y$ and $N$, respectively. We assume functional forms to estimate these functions, rather than treating them as parameters. For production in sector $X$ : $X=\bar{K}_{X} L_{X}^{1-\beta_{X}}$, where $\beta_{X} \in(0,1)$ is the inverse of the elasticity of labour demand. Clearly, $X_{1}=\left(1-\beta_{X}\right) \bar{K}_{X} L_{X}^{-\beta_{X}}$ and $X_{2}=L_{X}^{1-\beta_{X}}$. Combining equations (5) and (10) implies: $w / \lambda=p X_{1}$ $=Y_{1}=p_{n} N_{1}$. (See also equation (A12) in part $\mathrm{C}$ of the Appendix). It follows that $L_{X}^{\beta_{X}}=$ $\left(1-\beta_{X}\right) \bar{K}_{X} p \lambda w^{-1}$ and $L_{X}=\left[\left(1-\beta_{X}\right) \bar{K}_{X} p \lambda\right]^{\beta_{X}^{-1}} w^{-\beta_{X}^{-1}}=G\left(w, \bar{K}_{X}\right)$. Hence, $G_{1}=$ $-\beta_{X}^{-1}\left[\left(1-\beta_{X}\right) \bar{K}_{X} p \lambda\right]^{\beta_{X}^{-1}} w^{1-\beta_{X}{ }^{-1}}$ and $G_{2}=\beta_{X}^{-1}\left[\left(1-\beta_{X}\right) p \lambda\right]^{\beta_{X}^{-1}} K_{X}^{\beta_{X}{ }^{-1}-1} w^{-\beta_{X}{ }^{-1}}$. In a similar fashion, expressions for $Y_{1}, Y_{2}, N_{1}$ and $N_{2}$; as well as $H_{1}, H_{2}, J_{1}$ and $J_{2}$ are derived. ${ }^{18}$ Since there are no explicit data for sectoral employment levels, we estimate these components subject to the constraint that $L_{X}+L_{Y}+L_{N}=L$. In addition, most of the $\tau_{i}$ coefficients are functions of $\Phi$, where $\Phi / 1+\Phi$ represents the share of consumption expenditure on non-tradeables; this parameter is estimated as well.

In summary, the parameters that we estimate in our empirical analysis are $\beta_{X}, \beta_{Y}, \beta_{N}$ and 18 Simple functional forms are assumed in order to preserve degrees of freedom. In the specific factors
model, the only theoretical requirement is that production is concave in labour. 
$\Phi$. The model specified by the structural equations does not violate any time series properties as all the variables are I(1) and these variables are considered in differenced form in both equations of (16). Since $A_{B}>0$, we require that $\bar{L}-\lambda L>0$. This is guaranteed by rescaling the data for Union such that $\lambda \in\left(1,(1-U R)^{-1}\right) .{ }^{19}$ When estimating $\beta_{X}, \beta_{Y}, \beta_{N}$ and $\Phi$, we do not impose any other restrictions other than that for $\lambda$ and $L_{X}+L_{Y}+L_{N}=L$.

Moreover, we do not impose any sign restrictions as we examine the expected signs of each component of the models based solely on the data.

The parameters $\beta_{X}, \beta_{Y}, \beta_{N}$ and $\Phi$ are estimated using FIML. ${ }^{20}$ The estimates are subsequently substituted into each function to calibrate the effect of each variable on unemployment rate for each period. For example, in order to establish the effect of $p$ on $U R$, we calibrate the estimates of $\kappa_{p}$ for each period. That is,

$$
\frac{d \hat{U R} R_{t}}{d \hat{p}_{t}}=\frac{\hat{G}_{1, t} B_{t} A_{B, t}}{\left(1-A_{L, t}\left(\hat{G}_{1, t}+p_{t} \hat{H}_{1, t}+\frac{p_{t}}{p_{n, t}} \hat{J}_{1, t}\right) \bar{L}_{t}\right.},
$$

where $A_{B, t}=\left(\bar{L}_{t}-L_{t}\right) /\left(\bar{L}_{t}-\lambda_{t} L_{t}\right) p_{t}, A_{L, t}=\left(\lambda_{t}-1\right) \bar{L}_{t} B_{t} A_{B, t} /\left(\bar{L}_{t}-L_{t}\right)\left(\bar{L}_{t}-\lambda_{t} L_{t}\right)$, $\hat{G}_{1}=-\hat{\beta}_{X}^{-1}\left[\left(1-\hat{\beta}_{X}\right) \bar{K}_{X, t} p_{t} \lambda_{t}\right]^{\beta_{X}^{-1}} \hat{w}^{1-\hat{\beta}_{X}^{-1}}, \hat{H}_{1}=-\hat{\beta}_{Y}^{-1}\left[\left(1-\hat{\beta}_{Y}\right) \bar{K}_{Y, t} p_{t} \lambda_{t}\right]^{\beta_{Y}^{-1}} \hat{w}^{1-\hat{\beta}_{Y}^{-1}}$ and $\hat{J}_{1}=-\hat{\beta}_{N}^{-1}\left[\left(1-\hat{\beta}_{N}\right) \bar{K}_{N, t} p_{t} \lambda_{t}\right]^{\beta_{N}^{-1}} \hat{w}^{1-\hat{\beta}_{N}^{-1}}$.

The average effect of $p$ on $U R$ is found by taking the average of $d \hat{U R} R_{t} / d \hat{p}_{t}$. The corresponding test statistic for the null that the effect of $p$ on $U R$ is zero is

$$
Z=\frac{\left(\sum_{t=1}^{T} \frac{d \hat{U R} R_{t}}{d \hat{p}_{t}}\right) / T}{\hat{\sigma} / \sqrt{T}},
$$

where $\hat{\sigma}$ denotes the standard deviation of $d \hat{U R_{t}} / d \hat{p}_{t}$. In order to examine the sensitivity of our calibrated results, we also report the minimum and maximum values of $d \hat{U R_{t}} / d \hat{p}_{t}$ for the entire time period. A similar approach is used to calibrate the effect of all other variables on the unemployment rate.

3.5.2. The structural estimates: The results are reported in table 5. Recall that the estimated parameters of the production functions are substituted into each function to calibrate the effect of each variable on the unemployment rate for each period. The FIML estimates of $\beta_{X}, \beta_{Y}, \beta_{N}$ and $\Phi$ appear in panel A. While none of the parameters were restricted in the estimation, all the $\beta$ s are on the unit interval as required by theory. The estimate of $\Phi$ implies that about 57 per cent of consumption expenditure is on non-tradeables.

19 The precise transformation used is $\lambda=x^{*} 0.01^{*}$ Union $+y$, where $x=\frac{\max \left((1-U R)^{-1}\right)-\min \left((1-\text { UR })^{-1}\right)}{\max \left(0.01^{*} \text { Union }\right)-\min \left(0.01^{*} \text { Union }\right)}$ and $y=\left(\min \left((1-U R)^{-1}\right)-\min \left(0.01^{*} \text { Union }\right)\right)^{*} x$. As required by the theory, for the structural estimation we use the unlogged sectoral capital stocks as well as the level of unemployment benefits in lieu of the unemployment benefit replacement rate.

${ }^{20}$ Due to the recursive structure implied by equation (16), we also used non-linear least squares techniques using maximum likelihood procedures. The results were unchanged. 
Panel B reveals that $G_{1}<0, G_{2}>0, H_{1}<0, H_{2}>0, J_{1}<0$ and $J_{2}>0$, also as required by theory. The impact of greater capital accumulation on employment is biggest in sector $Y$ and smallest in sector $N$. Panel $C$ gives the estimates of equation (16), i.e., the $\hat{\kappa}$ and $\hat{\tau}$. For the $\hat{\kappa}$, all the coefficient signs are as predicted (see equation (A16) in the Appendix). This includes the finding that increases in the labour supply raise the unemployment rate (unlike what was found for the reduced form results). For the $\hat{\tau}$, the coefficients for ToT and the capital stocks in the three sectors also as predicted. The predicted signs of the other three variables were ambiguous (see equation (A22) in the Appendix).

Most important are the set of results appearing in panel D, these results capture the total effect of each of the variables on the unemployment rate. Since $U R$ is a function of $p_{n}$, the final impact of any variables is given by the relevant $\hat{\tau}$ as well as $\hat{\kappa}_{p_{n}}$. The estimates shown in the final panel are:

$$
\frac{d U R}{d i}=\frac{\kappa_{i}+\tau_{i} \kappa_{p_{n}}}{1-\kappa_{p_{n}} \tau_{u}}, i=B, T o T, \lambda, \bar{L}, \bar{K}_{X}, \bar{K}_{Y}, \bar{K}_{N} .
$$

With the exception of the results for the labour supply and the capital stock in the non-tradeables sector, the sign patterns are concordant with the reduced form results. They also completely conform to the theoretical predictions summarised in Proposition 2.

Note that the results for $B$ are exactly that, i.e., for average unemployment benefits, rather than the $B R R$, the unemployment benefit replacement rate. Focussing on the mean estimates in the second column, a ten per cent increase in the latest value of $B$ raises $U R$ by approximately 0.67 percentage points (i.e., $3.96^{*} 0.017$ ). ${ }^{21}$ More directly comparable is the result for ToT. A ten per cent improvement in ToT reduces the unemployment rate by approximately 0.74 percentage points (i.e., $0.0694^{*}-0.106$ ). Surprisingly, despite the very different estimation procedures, this estimated effect is similar to that implied by the reduced form estimates. In addition, the effect of a further ten per cent fall in the most recent value unionisation $(\lambda)$ on UR is a statistically significant, albeit economically small 0.04 percentage points ( $c f .0 .06$ percentage points for the reduced form estimates). The effects of a ten per cent increase in the most recent values of the capital stock in sectors $X$ and $Y$ are respectively, -0.3 and -0.5 percentage points. The effect of capital accumulation in the non-tradeables sector is positive, but is not a statistically robust effect. One advantage of the structural approach is that we can see that the latter effect occurs due to the fact that $J_{2}$ is extremely small (see Panel B), i.e., capital accumulation in the non-tradeables sector barely boosts labour demand.

Overall, the effects are entirely consistent with the reduced form findings. One caveat is that were we to use the median, rather than the mean, values of the coefficient estimates that the estimated effects of the variables on the unemployment rate are marginally smaller (with the exception of $\lambda$ ). Notwithstanding, the effects are still economically large. The results in the minimum and maximum columns of panel $\mathrm{D}$ also reveal that the coefficient signs are robust, with the exception of that for capital accumulation in the non-tradeables sector - but that was predicted by the theory as well.

${ }^{21}$ Note that all of the raw data were rescaled for the purpose of the structural estimation. One reason, already mentioned, was the necessity to rescale Union so that it conformed to the definition of $\lambda$ in the model. Another reason is that the sectoral capital stocks appear in the model in unlogged form. 
3.6. Overview. The finding on the importance of external trading conditions for unemployment is one of the two most prominent and robust findings in this paper. The result is also consistent with Nickell et al. (2005), who emphasise the importance of labour demand as well as labour market institutions (particularly, unionisation and the unemployment benefits system) in mediating the effects of shocks to the equilibrium unemployment rate. In terms of more liberalised trade policy and trade openness, Davidson and Matusz (2011) note that not only has the theoretical literature yet to reach any firm consensus on how trade impacts the unemployment rate, but that what little empirical evidence exists is limited and contradictory. ${ }^{22}$ Hopefully, the findings in this paper start to address this deficit of empirical research. The other key finding is that reductions in unemployment benefits and the unemployment benefit replacement rate were also significant and robust drivers of the lower unemployment rate.

\section{Conclusion}

What determines the equilibrium rate of unemployment? The narrowest interpretation of the natural rate hypothesis suggests that only supply-side influences should be important. In Australia at least, the unemployment rate fell dramatically while its trade relationship with China grew in the decade preceding the GFC. Outwardly, this suggests that the demand for resources and trade have been important drivers of the falling rate of unemployment. We have examined this proposition by developing a model with a booming external sector and a lagging manufacturing sector. This has a precedent in the large Dutch disease literature for countries with a dominant and growing exporting sector and a shrinking manufacturing sector. These features are evident for Australia.

The focus in this paper has been squarely on unemployment. Traditional trade models, as well as the Dutch disease literature, assume away unemployment (or in the latter case, if it is treated at all, it is done so in an ad hoc manner by assuming that wages are fixed). In this paper, unemployment results because of firm-union bargaining. In fact, all of the most familiar models of bargaining imply that wages are simply a mark-up over reservation wages. While this is a far from novel insight, we show how this is an important building block for understanding why wages and unemployment are inversely related. It also makes it transparent how the demand-side, and international trade, can influence the equilibrium rate of unemployment. As Nickell et al. (2005, p.22) note "unemployment is always determined by (long-run shifts in) aggregate demand". Our model predicts that a sustained improvement in the terms of trade will lower the equilibrium rate of unemployment.

Using data for Australia for the period 1960-2008, vector error correction model estimates indicated that a lower rate of unionisation, a lower unemployment benefit replacement rate and capital accumulation, particularly in the tradeables industries, reduce unemployment. Requiring more future research was the finding that capital accumulation in tradeable goods

22 One published study is Dutt et al. (2009) which uses cross-country panel data on unemployment and trade policy and finds that greater openness leads to more unemployment in the short run, but to a reduction in steady-state unemployment. Their latter finding is certainly consistent with our findings. On the other hand, we find no short-run deleterious effect of changes in the terms of trade on equilibrium unemployment. Our results are consistent with those of Felbermayr et al. (2009) which presents "overwhelming evidence" that higher trade openness is causally associated with a lower structural rate of unemployment. 
industries had a far stronger beneficial impact on reducing unemployment than did capital accumulation in the non-tradeable and services sector of the economy.

Most importantly, we found strong evidence that higher terms of trade lower the equilibrium rate of unemployment. Specifically, rising export prices have been an important factor driving reductions in the rate of unemployment. Interestingly, so too have falling import prices. These effects underscore the importance of Australia's growing trade exposure to China for improvements in its domestic labour market and for falls in its rate of unemployment.

All of the reduced form findings were validated by our structural equation estimates. The structural model used a combination of maximum likelihood estimation and calibration. Once again, the findings for the terms of trade and unemployment benefits were the strongest of the findings. These two factors have been the most important drivers of changes in the long-run rate of unemployment. 


\section{References}

Blanchard, O.; Katz, L.F., 1997. What we know and do not know about the natural rate of unemployment. Journal of Economic Perspectives 11(1), 51-72.

Blanchflower, D.G.; Oswald, A.J., 1995. An introduction to the wage curve. Journal of Economic Perspectives 9(3), 153-67.

Blanchflower, D.G.; Oswald, A.J.; Sanfey, P., 1996. Wages, profits, and rent-sharing. Quarterly Journal of Economics 111(1), 227-51.

Carter, M., 1995. An expository note on the composite commodity theorem. Economic Theory 5(1), 175-9.

Cordon, W.M., 1984. Booming sector and Dutch disease economics: survey and consolidation. Oxford Economic Papers 36(3), 359-80.

Cordon, W.M.; Neary, J.P., 1982. Booming sector and de-industrialisation in a small open economy. Economic Journal 92(368), 825-48.

Davidson, C.; Martin, L.; Matusz, S., 1999. Trade and search generated unemployment. Journal of International Economics 48(2), 271-99.

Davidson, C.; Matusz, S., 2011. Trade and labour markets. Forthcoming in Bernhofen, D.; Falvey, R.; Greenaway, D.; Kreickemeier, U., eds., Palgrave Handbook of International Trade.

Dreher, A.; Gaston, N. (2007). Has globalisation really had no effect on unions? Kyklos 60(2), 165-86.

Dutt, P.; Mitra, D.; Ranjan, P., 2009. International trade and unemployment: theory and cross-national evidence. Journal of International Economics 78(1), 32-44.

European Economic Advisory Group (EEAG), 2008. The EEAG Report on the European Economy 2008. Berlin: European Economic Advisory Group at CESifo.

Farber, H.S., 1986. The analysis of union behavior. In Ashenfelter, O.C.; Layard, R., eds., Handbook of Labor Economics 2. New York: Elsevier Science Publishers, 1039-89.

Felbermayr, G.; Prat, J.; Schmerer, H.-J., 2009, Trade and unemployment: what do the data say? IZA discussion paper no.4184.

Gaston, N.; Rajaguru, G., 2009. The long-run determinants of Australian inequality. Economic Record 85(270), 260-75.

Gaston, N.; Trefler, D., 1995. Union wage sensitivity to trade and protection: theory and evidence. Journal of International Economics 39(1/2), 1-25.

Gregory, R.G., 1976. Some implications of the growth of the mineral sector. Australian Journal of Agricultural Economics 20(2), 71-91.

Helpman, E.; Itskhoki, O., 2010. Labor market rigidities, trade and unemployment. Review of Economic Studies 77(3), 1100-37.

Hoon, H.T., 2001a. Adjustment of wages and equilibrium unemployment in a Ricardian global economy. Journal of International Economics 54(1), 193-209.

Hoon, H.T., 2001b. General-equilibrium implications of international product-market competition for jobs and wages. Oxford Economic Papers 53(1), 138-56. 
Johansen, S.; Juselius, K., 1990. Maximum likelihood estimation and inference on co-integration - with applications to the demand for money. Oxford Bulletin of Economics and Statistics 52(2), 169-210.

Kee, H.L.; Hoon, H.T., 2005. Trade, capital accumulation and structural unemployment: an empirical study of the Singapore economy. Journal of Development Economics 77(1), 125-52.

Marcellino, M., 1999. Some consequences of temporal aggregation in empirical analysis. Journal of Business \& Economic Statistics 17(1), 129-36.

Martin, J., 1996. Measures of replacement rates for the purpose of international comparisons: a note. OECD Economic Studies 26, 99-115.

Matusz, S.J., 1985. The Heckscher-Ohlin-Samuelson model with implicit contracts. Quarterly Journal of Economics 100(4), 1313-29.

McDonald, I.M., 2002. Equilibrium unemployment: theory and measurement in Australia using the Phillips curve. Economic Record 78(243), 451-70.

McDonald, I.M.; Solow, R.M., 1981. Wage bargaining and employment. American Economic Review 71(5), 896-908.

Mehlum, H.; Moene, K.; Torvik, R., 2006. Institutions and the resource curse. Economic Journal 116(508), 1-20.

Moore, M.; Ranjan, P., 2005. Globalisation and skill-biased technological change: implications for unemployment and wage inequality. Economic Journal 115(503), 391-422.

Mortensen, D.; Pissarides, C., 1994. Job creation and job destruction in the theory of unemployment. Review of Economic Studies 61(3), 397-416.

Nickell, S.J.; Layard, R., 1999. Labor market institutions and economic performance. In Ashenfelter, O.; Card, D., editors, Handbook of Labor Economics, volume 3C, 3029-84.

Nickell, S.; Nunziata, L.; Ochel, W., 2005. Unemployment in the OECD since the 1960s. What do we know? Economic Journal 115(500), 1-27.

Rajaguru, G.; Abeysinghe, T., 2008. Temporal aggregation, cointegration and causality inference. Economics Letters 101(3), 223-6.

Snape, R.H., 1977. Effects of mineral development on the economy. Australian Journal of Agricultural Economics 21(3), 147-56. 


\section{Appendix}

\section{A. Alternative bargaining models}

There are two cases of equation (4). In the 'normal' case, $m$ is assumed to be sufficiently high so that all workers have a probability of being unemployed equal to $(m-l) / m$. When $l \geq m$, however, all union members are employed. In this case, the union is completely wageoriented and maximises $m U(w)$. Noting that $U_{l}=0$, equation (3) yields

$$
\pi_{l}=0 \text { or } p x_{l}=w,
$$

i.e., labour is employed until its marginal revenue product equals the wage. The wage equals

$$
w=\frac{\eta(1-\varphi) \omega}{\eta-\varphi} .
$$

Since $\eta>\varphi$, the negotiated wage is some multiple of the reservation wage (albeit, a larger multiple compared to the case when $l<m){ }^{23}$

In fact, the wage is a multiple of the reservation wage regardless of whether bargaining is efficient or whether unions negotiate over wages alone. For example, in the right-to-manage model, the union maximises its utility subject to $\pi_{l}=w$. It is straightforward to show that $w=\omega\left(1+\xi^{-1}\right)^{-1}$, where $\xi(<-1)$ is the elasticity of labour demand. Hence, the wage is a mark-up over the reservation wage.

\section{B. Proof of Proposition 1}

Assuming $I$ identical firms in sector $X$ and $I^{\prime}$ identical firms in sector $Y$, the sectoral employment of the factors as well as production of each good is

$$
\begin{aligned}
& \bar{K}_{X}=\sum_{i=1}^{I} \bar{k}_{x} \text { and } \bar{K}_{Y}=\sum_{i^{\prime}=1}^{I^{\prime}} \bar{k}_{y} ; L_{X}=\sum_{i=1}^{I} l_{x}, L_{Y}=\sum_{i^{\prime}=1}^{I^{\prime}} l_{y} \text { and } L_{X}+L_{X}=L \leq \bar{L} ; \\
& X=\sum_{i=1}^{I} x=I x \text { and } Y=\sum_{i^{\prime}=1}^{I^{\prime}} y=I^{\prime} y,
\end{aligned}
$$

where an over-score denotes a variable being in fixed supply. Note that equation (10) can be rewritten as

$$
w=\frac{\lambda(\bar{L}-L) B}{\bar{L}-\lambda L} .
$$

From equation (5), we have

$$
\frac{w}{\lambda}=p X_{1}\left(L_{X}, \bar{K}_{X}\right)=Y_{1}\left(L_{Y}, \bar{K}_{Y}\right) .
$$

Now define the following inverse functions that are used to isolate sectoral labour demands: $G \equiv X_{1}^{-1}$ and $H \equiv Y_{1}^{-1}$, where $G_{1}<0, G_{2}>0, H_{1}<0$ and $H_{2}>0$ (and the subscripts denote derivatives with respect to the first and second arguments).

${ }_{23}$ Once again, $w-\varphi(\tilde{\pi} / l)-(1-\varphi) \omega=0\left(^{+}\right)$. Since $\tilde{\pi}_{l}=w$, equation (A2) follows. Second-order conditions in this case also require $\eta<1$. Moreover, $\left(^{+}\right)$can be written as $\eta-\varphi-(1-\varphi) w l(\tilde{\pi})^{-1}=0$ which implies that $\eta>\varphi$. 
Let $Z(w,)=.G(w,)+.H(w,$.$) . Then \frac{d Z(w, .)}{d w}<0$, since $\frac{d G(w, .)}{d w}<0$ and $\frac{d H(w, .)}{d w}<0$.

Moreover, we know (from equation (A4)) that $\frac{d w}{d L}<0$. Then, since $Z(L,)=.G(L,)+.H(L,$.$) ,$ we have by the chain rule $\frac{d Z(L, .)}{d L}=\frac{d Z(w, .)}{d w} \times \frac{d w}{d L}<0$. Also, since the production function is assumed to satisfy the Inada conditions we have $\lim _{L \rightarrow+\infty} Z(L,)=$.0 and $\lim _{L \rightarrow 0} Z(L,.) \rightarrow+\infty$. Now consider the following equation

$$
L=Z(L, .)
$$

The graph of the function on the left-hand side is the 45 degree line whereas the function on the right-hand side is always positive, monotonically decreasing and converges to zero. This guarantees the existence of an interior solution $L^{*}$ that solves equation (A6). Therefore, we can write total labour demand as

$$
L=L_{X}+L_{Y}=G\left(\frac{w}{p \lambda}, \bar{K}_{X}\right)+H\left(\frac{w}{\lambda}, \bar{K}_{Y}\right) .
$$

Using equation (A4) we have

$$
L=G\left(\frac{(\bar{L}-L) B}{p(\bar{L}-\lambda L)}, \bar{K}_{X}\right)+H\left(\frac{(\bar{L}-L) B}{(\bar{L}-\lambda L)}, \bar{K}_{Y}\right) .
$$

Totally differentiate equation (A8) to obtain

$$
\begin{gathered}
d L=G_{1}\left(A_{B} d B+A_{p} d p+A_{\lambda} d \lambda+A_{\bar{L}} d \bar{L}+A_{L} d L\right)+G_{2} d \bar{K}_{X} \\
+H_{1}\left(C_{B} d B+C_{\lambda} d \lambda+C_{\bar{L}} d \bar{L}+C_{L} d L\right)+H_{2} d \bar{K}_{Y}
\end{gathered}
$$

where $A_{B}=\frac{(\bar{L}-L)}{(\bar{L}-\lambda L) p}>0 ; A_{p}=-\frac{(\bar{L}-L) B}{(\bar{L}-\lambda L) p^{2}}=-\frac{A_{B} B}{p}<0 ; A_{\lambda}=\frac{(\bar{L}-L) B L}{(\bar{L}-\lambda L)^{2} p}=\frac{A_{B} B L}{(\bar{L}-\lambda L)}>0$;

$A_{\bar{L}}=\frac{(1-\lambda) B L}{(\bar{L}-\lambda L)^{2} p}=\frac{A_{B}(1-\lambda) B L}{(\bar{L}-L)(\bar{L}-\lambda L)}<0 ; \quad A_{L}=\frac{(\lambda-1) B \bar{L}}{(\bar{L}-\lambda L)^{2} p}=\frac{A_{B}(\lambda-1) B \bar{L}}{(\bar{L}-L)(\bar{L}-\lambda L)}=-\frac{A_{\bar{L}} \bar{L}}{L}>0 ;$

$C_{B}=p A_{B}>0 ; C_{\lambda}=p A_{\lambda}>0 ; C_{\bar{L}}=p A_{\bar{L}}<0$ and $C_{L}=p A_{L}>0$.

Since $u=\frac{\bar{L}-L}{\bar{L}}$, then $d u=\frac{L d \bar{L}-\bar{L} d L}{\bar{L}^{2}}$, so that $d L=(1-u) d \bar{L}-\bar{L} d u$. Hence, equation (A9) can be rewritten as

$$
\begin{array}{r}
\left(1-G_{1} A_{L}-H_{1} C_{L}\right) \bar{L} d u=\left(1-G_{1} A_{L}-H_{1} C_{L}\right)(1-u) d \bar{L}-G_{1}\left(A_{B} d B+A_{p} d p+A_{\lambda} d \lambda+A_{\bar{L}} d \bar{L}\right) \\
-G_{2} d \bar{K}_{X}-H_{1}\left(C_{B} d B+C_{\lambda} d \lambda+C_{\bar{L}} d \bar{L}\right)-H_{2} d \bar{K}_{\gamma} .
\end{array}
$$

This can be simplified as ${ }^{24}$

\footnotetext{
${ }^{24}$ We ignore here the indirect impact of $p$ on $\lambda$. While the impact of higher product prices is to raise employment, there is a well-known wage indeterminacy with respect to higher product prices (see Gaston and Trefler, 1995, e.g.). However, the wage is higher the greater is union bargaining strength and the better is the reservation alternative wage. Moreover, higher prices unambiguously benefit the union and the firm. Finally, note that in the case of an iso-elastic labour demand schedule (e.g., when the underlying technology is Cobb-Douglas), there is no impact on the
} 


$$
\begin{aligned}
\left(1-\left(G_{1}+p H_{1}\right) A_{L}\right) \bar{L} d u= & (1-u) d \bar{L}-G_{1} A_{p} d p-\left(G_{1}+p H_{1}\right)\left(A_{B} d B+A_{\lambda} d \lambda\right) \\
& -G_{2} d \bar{K}_{X}-H_{2} d \bar{K}_{Y} .
\end{aligned}
$$

Since $\left(1-\left(G_{1}+p H_{1}\right) A_{L}\right) \bar{L}>0$, it follows that: $u_{B}>0, u_{p}<0, u_{\lambda}>0, u_{\bar{L}}>0, u_{\bar{K}_{X}}<0$ and $u_{\bar{K}_{Y}}<0$.

\section{Proof of Proposition 2}

Proceed as for the proof of Proposition 1. First, we have

$$
\frac{w}{\lambda}=p X_{1}\left(L_{X}, \bar{K}_{X}\right)=Y_{1}\left(L_{Y}, \bar{K}_{Y}\right)=p_{n} N_{1}\left(L_{N}, \bar{K}_{N}\right),
$$

where $p=p_{X} / p_{Y}$ and $p_{n}=p_{N} / p_{Y}$. Next define the inverse function for the non-tradeables sector: $J \equiv N_{1}^{-1}$, where $J_{1}<0$ and $J_{2}>0$. Total labour demand is

$$
L=G\left(\frac{(\bar{L}-L) B}{p(\bar{L}-\lambda L)}, \bar{K}_{X}\right)+H\left(\frac{(\bar{L}-L) B}{(\bar{L}-\lambda L)}, \bar{K}_{Y}\right)+J\left(\frac{(\bar{L}-L) B}{p_{n}(\bar{L}-\lambda L)}, \bar{K}_{N}\right) .
$$

Totally differentiate to obtain

$$
\begin{aligned}
d L=G_{1}( & \left.A_{B} d B+A_{p} d p+A_{\lambda} d \lambda+A_{\bar{L}} d \bar{L}+A_{L} d L\right)+G_{2} d \bar{K}_{X} \\
& +H_{1}\left(C_{B} d B+C_{\lambda} d \lambda+C_{\bar{L}} d \bar{L}+C_{L} d L\right)+H_{2} d \bar{K}_{Y} \\
& +J_{1}\left(D_{B} d B+D_{p_{n}} d p_{n}+D_{\lambda} d \lambda+D_{\bar{L}} d \bar{L}+D_{L} d L\right)+J_{2} d \bar{K}_{N},
\end{aligned}
$$

where $D_{B}=\frac{p A_{B}}{p_{n}}>0 ; D_{p_{n}}=\frac{p^{2} A_{p}}{p_{n}^{2}}<0 ; D_{\lambda}=\frac{p A_{\lambda}}{p_{n}}>0 ; D_{\bar{L}}=\frac{p A_{\bar{L}}}{p_{n}}<0$ and $D_{L}=\frac{p A_{L}}{p_{n}}>0$.

Rearranging equation (A14) gives

$$
E_{L} d L=E_{B} d B+E_{p} d p+E_{\lambda} d \lambda+E_{\bar{L}} d \bar{L}+G_{2} d \bar{K}_{X}+H_{2} d \bar{K}_{Y}+J_{2} d \bar{K}_{N}+E_{p_{n}} d p_{n} .
$$

Since $d L=(1-u) d \bar{L}-\bar{L} d u$, this can be rewritten as

$$
E_{L}(\bar{L} d u)=(1-u) d \bar{L}-E_{B} d B-E_{p} d p-E_{\lambda} d \lambda-G_{2} d \bar{K}_{X}-H_{2} d \bar{K}_{Y}-J_{2} d \bar{K}_{N}-E_{p_{n}} d p_{n} .
$$

Defining $\delta_{2}=\left(G_{1}+p H_{1}+\frac{p}{p_{n}} J_{1}\right)<0, \quad E_{L}=\left(1-\delta_{2} A_{L}\right)>0 ; \quad E_{B}=\delta_{2} A_{B}<0 ; \quad E_{p}=G_{1} A_{p}>0 ;$ $E_{\lambda}=\delta_{2} A_{\lambda}<0$ and $E_{p_{n}}=J_{1} D_{p_{n}}>0$.

Consumers derive utility from non-tradeable services and tradeable goods. Utility is assumed to take the Cobb-Douglas form

$$
U\left(c_{n}, c_{t}\right)=c_{n}^{\phi} c_{t}^{1-\phi},
$$

where the tradeable good is a composite commodity. For a small open economy, exportables and importables represent a group of goods whose relative prices are given and can thus be

elasticity of labour demand and no effect on $\lambda$ in the right-to-manage model. Noteworthy from an empirical viewpoint is the fact that in the VEC model results, the long-run impact of ToT on Union is statistically insignificant. This is in line with findings that globalisation, broadly defined, has not affected union membership in a panel of OECD countries (Dreher and Gaston, 2007). 
treated as one commodity, i.e., $t=p X+Y$ (Carter, 1995). The relative demand for non-tradeables is

$$
\frac{c_{n}}{c_{t}}=\frac{\Phi}{p_{n}}
$$

where $\Phi=\phi /(1-\phi)$. The relative supply of non-tradeables is

$$
\frac{q_{n}}{q_{t}}=\frac{N\left(L_{N}, \bar{K}_{N}\right)}{p X\left(L_{X}, \bar{K}_{X}\right)+Y\left(L_{Y}, \bar{K}_{Y}\right)} .
$$

The equilibrium relative price of non-tradeables is determined by the equality of relative demand and relative supply, i.e.,

$$
p_{n}=\frac{\Phi\left(p X\left(L_{X}, \bar{K}_{X}\right)+Y\left(L_{Y}, \bar{K}_{Y}\right)\right)}{N\left(L_{N}, \bar{K}_{N}\right)} .
$$

Totally differentiate to obtain

$$
\begin{aligned}
N d p_{n}+p_{n} & \left\lfloor N_{1}\left(J_{1}\left(D_{B} d B+D_{p_{n}} d p_{n}+D_{\lambda} d \lambda+D_{\bar{L}} d \bar{L}+D_{L} d L\right)+J_{2} d \bar{K}_{N}\right)+N_{2} d \bar{K}_{N}\right\rfloor \\
= & \Phi X d p+\Phi p\left[X_{1}\left(G_{1}\left(A_{B} d B+A_{p} d p+A_{\lambda} d \lambda+A_{\bar{L}} d \bar{L}+A_{L} d L\right)+G_{2} d \bar{K}_{X}\right)+X_{2} d \bar{K}_{X}\right\rfloor \\
& +\Phi\left[Y_{1}\left(H_{1}\left(C_{B} d B+C_{\lambda} d \lambda+C_{\bar{L}} d \bar{L}+C_{L} d L\right)+H_{2} d \bar{K}_{Y}\right)+Y_{2} d \bar{K}_{Y}\right] .
\end{aligned}
$$

Collecting terms, we have

$$
R_{p_{n}} d p_{n}=R_{B} d B+R_{p} d p+R_{\lambda} d \lambda+R_{\bar{L}} d \bar{L}+R_{L} d L+R_{\bar{K}_{X}} d \bar{K}_{X}+R_{\bar{K}_{Y}} d \bar{K}_{Y}+R_{\bar{K}_{N}} d \bar{K}_{N},
$$

where $R_{p_{n}}=N+p_{n} N_{1} J_{1} D_{p_{n}}>0$, and by defining $\delta_{3}=\Phi\left(X_{1} G_{1}+Y_{1} H_{1}\right)-N_{1} J_{1}, R_{B}=\delta_{3} p A_{B}$;

$R_{p}=\Phi\left(X+p X_{1} G_{1} A_{p}\right)>0 ; R_{\lambda}=\delta_{3} p A_{\lambda} ; R_{\bar{L}}=\delta_{3} p A_{\bar{L}} ; R_{L}=\delta_{3} p A_{L} ;$

$R_{\bar{K}_{X}}=\Phi p\left(X_{1} G_{2}+X_{2}\right)>0 ; R_{\bar{K}_{Y}}=\Phi\left(Y_{1} H_{2}+Y_{2}\right)>0$ and $R_{\bar{K}_{N}}=-p_{n}\left(N_{1} J_{2}+N_{2}\right)<0$.

Note that $R_{\bar{L}} d \bar{L}+R_{L} d L=\delta_{3} p\left(A_{\bar{L}} d \bar{L}+A_{L} d L\right)=\delta_{3} p A_{L}\left(\frac{\bar{L} d L-L d \bar{L}}{\bar{L}}\right)=-\delta_{3} p \bar{L} A_{L} d u=R_{u} d u$. Hence, equation (A22) can be rewritten as

$$
R_{p_{n}} d p_{n}=R_{B} d B+R_{p} d p+R_{\lambda} d \lambda+R_{\bar{K}_{X}} d \bar{K}_{X}+R_{\bar{K}_{Y}} d \bar{K}_{Y}+R_{\bar{K}_{N}} d \bar{K}_{N}+R_{u} d u,
$$

Stacking equations (A16) and (A23) in matrix form:

$$
\left[\begin{array}{cc}
E_{L} \bar{L} & E_{p_{n}} \\
-R_{u} & R_{p_{n}}
\end{array}\right]\left[\begin{array}{c}
d u \\
d p_{n}
\end{array}\right]=\left[\begin{array}{ccccccc}
-E_{B} & -E_{p} & -E_{\lambda} & (1-u) & -G_{2} & -H_{2} & -J_{2} \\
R_{B} & R_{p} & R_{\lambda} & 0 & R_{\bar{K}_{X}} & R_{\bar{K}_{Y}} & R_{\bar{K}_{N}}
\end{array}\right] d M^{\prime},
$$

where $d M=\left\lfloor\begin{array}{lllllll}d B & d p & d \lambda & d \bar{L} & d \bar{K}_{X} & d \bar{K}_{Y} & d \bar{K}_{N}\end{array}\right\rfloor$. The determinant is $\bar{L} E_{L} R_{p_{n}}+E_{p_{n}} R_{u}=N \bar{L}\left(1-\delta_{1} A_{L}\right)+J_{1} D_{p_{n}} \bar{L}\left[p_{n} N_{1}-A_{L} \delta_{5}\right]>0$, where $\delta_{5}=\left(p_{n} N_{1} \delta_{1}+\delta_{3} p\right)$. Using Cramer's rule it can be shown that: $u_{B}>0, u_{p}<0, u_{\lambda}>0, u_{\bar{L}}>0, u_{\bar{K}_{X}}<0$ and $u_{\bar{K}_{Y}}<0$. However, an increase in $K_{N}$ has an indeterminate effect on unemployment, i.e., part e) of Proposition 2. 


\section{Coefficients to be estimated in equation (16)}

First, define the following: $\delta_{1}=E_{L} \bar{L}=\left(1-A_{L} \delta_{2}\right) \bar{L}>0, \quad \delta_{2}=\left(G_{1}+p H_{1}+\frac{p}{p_{n}} J_{1}\right)<0$, $\delta_{3}=\Phi\left(X_{1} G_{1}+Y_{1} H_{1}\right)-N_{1} J_{1}$ and $\delta_{4}=R_{p_{n}}=N+p_{n} N_{1} J_{1} D_{p_{n}}>0$. Secondly, note that $A_{B}=\frac{(\bar{L}-L)}{(\bar{L}-\lambda L) p}, \quad A_{L}=\frac{(\lambda-1) \bar{L} B A_{B}}{(\bar{L}-L)(\bar{L}-\lambda L)}$ and $D_{p_{n}}=-\frac{p B A_{B}}{p_{n}^{2}}<0$. The marginal products are all positive, i.e., $X_{1}>0, X_{2}>0, Y_{1}>0, Y_{2}>0, N_{1}>0$ and $N_{2}>0$; in addition, note that $G_{1}<0, G_{2}>0, H_{1}<0, H_{2}>0, J_{1}<0$ and $J_{2}>0$.

\begin{tabular}{|c|l|}
\hline \multicolumn{2}{|c|}{ Coefficients in Unemployment equation } \\
\hline$\kappa_{B}$ & $-\frac{E_{B}}{\delta_{1}}$, where $E_{B}=\delta_{2} A_{B}<0$ \\
\hline$\kappa_{p}$ & $-\frac{E_{p}}{\delta_{1}}$, where $E_{p}=G_{1} A_{p}>0$ and $A_{p}=-\frac{B A_{B}}{p}<0$ \\
\hline$\kappa_{\lambda}$ & $-\frac{E_{\lambda}}{\delta_{1}}$, where $E_{\lambda}=\delta_{2} A_{\lambda}<0$ and $A_{\lambda}=\frac{B L A_{B}}{(\bar{L}-\lambda L)}>0$ \\
\hline$\kappa_{\bar{L}}$ & $\frac{(1-u)}{\delta_{1}}$ \\
\hline$\kappa_{\bar{K}_{X}}$ & $-\frac{G_{2}}{\delta_{1}}$ \\
\hline$\kappa_{\bar{K}_{Y}}$ & $-\frac{H_{2}}{\delta_{1}}$ \\
\hline$\kappa_{\bar{K}_{N}}$ & $-\frac{J_{2}}{\delta_{1}}$ \\
\hline$\kappa_{p_{n}}$ & $-\frac{E_{p_{n}}}{\delta_{1}}$, where $E_{p_{n}}=\frac{J_{1} p^{2} A_{p}}{p_{n}^{2}}>0$ and $A_{p}=-\frac{B A_{B}}{p}<0$ \\
\hline
\end{tabular}




\begin{tabular}{|c|l|}
\hline \multicolumn{2}{|c|}{ Coefficients in Price of Non-tradeables equation } \\
\hline$\tau_{B}$ & $\frac{R_{B}}{\delta_{4}}$, where $R_{B}=\delta_{3} p A_{B}$ \\
\hline$\tau_{p}$ & $\frac{R_{p}}{\delta_{4}}$, where $R_{p}=\Phi\left(X+p X_{1} G_{1} A_{p}\right)>0$ and $A_{p}=-\frac{B A_{B}}{p}<0$ \\
\hline$\tau_{\lambda}$ & $\frac{R_{\lambda}}{\delta_{4}}$, where $R_{\lambda}=\delta_{3} p A_{\lambda}$ and $A_{\lambda}=\frac{B L A_{B}}{(\bar{L}-\lambda L)}>0$ \\
\hline$\tau_{\bar{K}_{X}}$ & $\frac{R_{\bar{K}_{X}}}{\delta_{4}}$, where $R_{\bar{K}_{X}}=\Phi p\left(X_{1} G_{2}+X_{2}\right)>0$ \\
\hline$\tau_{\bar{K}_{Y}}$ & $\frac{R_{\bar{K}_{Y}}}{\delta_{4}}$, where $R_{\bar{K}_{Y}}=\Phi\left(Y_{1} H_{2}+Y_{2}\right)>0$ \\
\hline$\tau_{\bar{K}_{N}}$ & $\frac{R_{\bar{K}_{N}}}{\delta_{4}}$, where $R_{\bar{K}_{N}}=-p_{n}\left(N_{1} J_{2}+N_{2}\right)<0$ \\
\hline$\tau_{u}$ & $\frac{R_{u}}{\delta_{4}}$, where $R_{u}=-\delta_{3} p \bar{L}_{L}$ \\
\hline
\end{tabular}




\section{$\underline{\text { Tables and Figures }}$}

Table 1. Descriptive statistics

\begin{tabular}{|c|c|c|c|c|c|c|}
\hline Label & Mean & Std.Dev. & Median & Minimum & Maximum & $\begin{array}{c}\text { Change } \\
1960-2008\end{array}$ \\
\hline$U R$ & 5.3 & 2.7 & 5.6 & 1.1 & 10.3 & $192 \%$ \\
\hline ToT & 69.4 & 8.9 & 67.9 & 55.3 & 100.0 & $40 \%$ \\
\hline$P_{X}$ & 45.7 & 26.8 & 48.7 & 11.8 & 100.0 & $716 \%$ \\
\hline$P_{Y}$ & 67.1 & 38.5 & 74.5 & 17.0 & 116.1 & $485 \%$ \\
\hline$P_{N T}$ & 51.7 & 34.8 & 49.8 & 9.2 & 110.1 & $1091 \%$ \\
\hline Union & 38.9 & 9.6 & 44.0 & 18.9 & 47.9 & $-60 \%$ \\
\hline$B R R^{*}$ & 21.9 & 4.0 & 22.9 & 13.6 & 27.2 & $16 \%$ \\
\hline$L F^{\ddagger}$ & 7364.5 & 2060.7 & 7131.5 & 4143.0 & 11257.6 & $172 \%$ \\
\hline Inflation & 5.4 & 4.0 & 4.0 & -0.7 & 16.9 & $19 \%$ \\
\hline$K_{-}$mining $\ddagger$ & 86356.4 & 60647.3 & 84241.0 & 4149.0 & 241764.0 & $5727 \%$ \\
\hline$K \_a g r^{\ddagger}$ & 65596.0 & 10656.1 & 70075.0 & 43325.0 & 85135.0 & $97 \%$ \\
\hline K_manuf $f^{\ddagger}$ & 75936.0 & 28349.3 & 73148.0 & 26970.0 & 139697.0 & $418 \%$ \\
\hline K_other ${ }^{\ddagger}$ & 703325.7 & 343720.5 & 673526.0 & 189132.0 & 1442937.0 & $663 \%$ \\
\hline K_total & 931214.1 & 442233.7 & 901809.0 & 263576.0 & 1909533.0 & $624 \%$ \\
\hline
\end{tabular}

Note: See Appendix table A1 for variable labels and data sources. * Data are for 1960-2008, except for the BRR data which are for 1961-2007. ${ }^{\ddagger}$ Logged in econometric work. The capital stock data are in millions of \$AU and the labour force data are in thousands. 
Table 2. Unit root tests

\begin{tabular}{l|ccc|ccc}
\hline & \multicolumn{3}{|c|}{ Levels } & \multicolumn{3}{c}{ First Differences } \\
\cline { 2 - 7 } & ADF & \multicolumn{1}{|c}{$\boldsymbol{P P}$} & KPSS & ADF & PP & KPSS \\
\hline UR & -1.45 & -1.49 & $0.29^{* * *}$ & $-5.48^{* * *}$ & $-5.26^{* * *}$ & 0.18 \\
$T o T$ & -0.01 & -0.41 & $0.28^{* * *}$ & $-3.69^{* * * *}$ & $-4.61^{* * *}$ & 0.17 \\
$P_{X}$ & -0.82 & -0.83 & $0.28^{* * *}$ & $-3.03^{* *}$ & $3.06^{* *}$ & 0.15 \\
$P_{Y}$ & -0.92 & -1.24 & $0.26^{* * *}$ & $-4.82^{* * *}$ & $-4.82^{* * *}$ & 0.19 \\
$P_{N}$ & -3.08 & -2.44 & $0.24^{* * *}$ & $-3.78^{* * *}$ & $-3.83^{* * *}$ & 0.20 \\
$P_{N} / P Y$ & -1.48 & -1.49 & $0.29^{* * *}$ & $-5.34^{* * *}$ & $-5.48^{* * *}$ & 0.13 \\
LK_mining & -2.84 & -2.56 & $0.23^{* * *}$ & $-3.84^{* * *}$ & $-3.73^{* * *}$ & 0.19 \\
LK_mining_agr & -3.10 & -1.98 & $0.23^{* * *}$ & $-4.08^{* * *}$ & $-3.98^{* * *}$ & 0.21 \\
LK_manuf & -3.13 & -2.99 & $0.24^{* * *}$ & $-3.98^{* * *}$ & $-3.98^{* * *}$ & 0.20 \\
LK_manuf_agr & -2.75 & -2.51 & $0.27^{* * *}$ & $3.90^{* * *}$ & $-3.90^{* * *}$ & 0.19 \\
LK_less_mining & -2.22 & -2.41 & $0.23^{* * *}$ & $-3.94^{* * *}$ & $3.96^{* * *}$ & 0.19 \\
LK_less_mining_agr & -2.31 & -2.64 & $0.24^{* * *}$ & $-3.99^{* * *}$ & $-4.00^{* * *}$ & 0.19 \\
LK_others & -2.41 & -2.42 & $0.23^{* * *}$ & $-3.52^{* *}$ & $-3.81^{* * *}$ & 0.20 \\
Union & -0.56 & -0.74 & $0.23^{* * *}$ & $-4.91^{* * *}$ & $-4.99^{* * *}$ & 0.15 \\
BRR & -2.28 & -1.23 & $0.24^{* * *}$ & $-3.67^{* * *}$ & $-3.85^{* * *}$ & 0.17 \\
LLF & -1.96 & -1.96 & $0.25^{* * *}$ & $-6.15^{* * *}$ & $-6.14^{* * *}$ & 0.16 \\
Inflation & $-4.16^{* * *}$ & $-4.45^{* * *}$ & 0.13 & & & \\
\hline
\end{tabular}

Notes:

(i) $P P$ test and $A D F$ test: $* * *, * * *$ indicates rejection of null of non-stationarity at $1 \%, 5 \%$ and $10 \%$ level of significance, respectively.

(ii) KPSS test: $* * *, * * * *$ indicates the rejection of null of stationarity at $1 \%, 5 \%$ and $10 \%$ level of significance, respectively.

Table 3. Johansen-Juselius procedure for testing co-integration

\begin{tabular}{c|ccccc|ccccc}
\hline & \multicolumn{5}{|c|}{ Trace Statistic } & \multicolumn{5}{c}{ Maximum Eigen Values Statistic } \\
\hline$U R \rightarrow$ & $(1)$ & $(2)$ & $(3)$ & $(4)$ & $(5)$ & $(1)$ & $(2)$ & $(3)$ & $(4)$ & $(5)$ \\
\hline $\mathrm{r}=0$ & $253.4^{* *}$ & $432.7^{* *}$ & $235.1^{* *}$ & $209.8^{* *}$ & $403.8^{* *}$ & $96.7^{* *}$ & $194.9^{* *}$ & $77.0^{* *}$ & $84.3^{* *}$ & $147.6^{* *}$ \\
$\mathrm{r} \leq 1$ & 156.7 & $237.8^{* *}$ & 158.1 & 125.4 & 256.3 & 31.7 & $83.7^{* *}$ & 35.1 & 31.0 & 99.6 \\
$\mathrm{r} \leq 2$ & 125.0 & 154.1 & 123.0 & 94.4 & 156.7 & 29.7 & 33.9 & 30.0 & 26.9 & 41.6 \\
$\mathrm{r} \leq 3$ & 95.3 & 120.2 & 93.0 & 67.5 & 115.1 & 27.8 & 30.3 & 28.0 & 24.6 & 35.8 \\
$\mathrm{r} \leq 4$ & 67.4 & 89.8 & 65.1 & 42.9 & 79.3 & 22.2 & 23.5 & 24.9 & 20.3 & 27.6 \\
$\mathrm{r} \leq 5$ & 45.2 & 66.3 & 40.2 & 22.5 & 51.8 & 16.9 & 23.1 & 21.1 & 11.9 & 23.2 \\
$\mathrm{r} \leq 6$ & 28.3 & 43.2 & 19.1 & 10.6 & 28.6 & 13.9 & 14.5 & 12.9 & 8.2 & 18.5 \\
$\mathrm{r} \leq 7$ & 14.4 & 28.6 & 6.2 & 2.4 & 10.1 & 11.6 & 13.1 & 3.7 & 2.4 & 7.7 \\
$\mathrm{r} \leq 8$ & 2.8 & 15.5 & 2.5 & & 2.4 & 2.8 & 12.8 & 2.5 & & 2.3 \\
$\mathrm{r} \leq 9$ & & 2.7 & & & 0.1 & & 2.7 & & & 0.1 \\
\hline
\end{tabular}

Notes: ${ }^{*}$ and ${ }^{* *}$ denotes the rejection of null at $5 \%$ and $1 \%$, respectively.

The baseline model is in Column (1), i.e., $U R, T o T, P_{N} / P_{Y}, L K \_m i n i n g, L K \_m a n u f \_a g r, L K \_o t h e r s, U n i o n, B R R, L L F, L e f t$ and an intercept. Column (2) includes Inflation. Column (3) uses alternative capital stock measures. Column (4): LLF is excluded.

Column (5): replaces ToT with disaggregated price series. 


\begin{tabular}{|c|c|c|c|c|c|c|}
\hline \multicolumn{7}{|c|}{$\begin{array}{l}\begin{aligned} \Delta U R_{t}= & \alpha_{11} e_{1 t-1}+\alpha_{21} e_{2 t-1}+\gamma_{11} \Delta U R_{t-1}+\gamma_{12} \Delta T_{o} T_{t}+\gamma_{13} \Delta\left(P_{N, t} / P_{Y, t}\right)+\gamma_{14} \Delta \ln K_{X, t} \\
& +\gamma_{15} \Delta \ln K_{Y, t}+\gamma_{16} \Delta \ln K_{N, t}+\gamma_{17} \Delta \text { Union }_{t}+\gamma_{18} \Delta B R R_{t}+\gamma_{19} \Delta \ln L F_{t}+\psi_{1} \text { Left }_{t}\end{aligned} \\
\text { where } e_{1 t}=U R_{t}-\beta_{2} T_{0} T_{t}-\beta_{3}\left(P_{N, t} / P_{Y, t}\right)-\beta_{4} \Delta \ln K_{X, t}-\beta_{5} \ln K_{Y, t}-\beta_{6} \ln K_{N, t} \\
\quad-\beta_{7} \text { Union }_{t}-\beta_{8} B R R_{t}-\beta_{9} \ln L F_{t}+\beta_{10} \text { Left }_{t} \text { and } e_{2 t}=\text { Inflation }_{t}\end{array}$} \\
\hline & & (1) & $(2)$ & (3) & $(4)$ & (5) \\
\hline \multirow{19}{*}{ 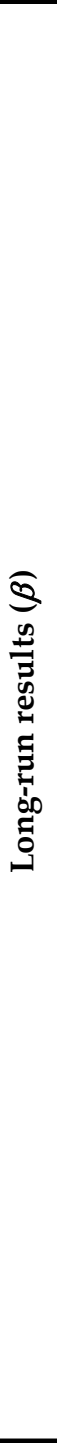 } & ToT & $\begin{array}{c}-0.15^{* * *} \\
(0.04)\end{array}$ & $\begin{array}{c}-0.12^{* * *} \\
(0.03)\end{array}$ & $\begin{array}{c}-0.11^{* * *} \\
(0.04)\end{array}$ & $\begin{array}{c}-0.09^{* * *} \\
(0.03)\end{array}$ & \\
\hline & $P_{N} / P_{Y}$ & $\begin{array}{l}0.06 \\
(0.05)\end{array}$ & $\begin{array}{l}0.002 \\
(0.05)\end{array}$ & $\begin{array}{l}0.05 \\
(0.05)\end{array}$ & $\begin{array}{c}0.02 \\
(0.05)\end{array}$ & \\
\hline & $P_{X}$ & & & & & $\begin{array}{l}-0.01^{*} \\
(0.005)\end{array}$ \\
\hline & $P_{Y}$ & & & & & $\begin{array}{l}0.02^{*} \\
(0.01)\end{array}$ \\
\hline & $P_{N}$ & & & & & $\begin{array}{c}-0.35^{* * *} \\
(0.09)\end{array}$ \\
\hline & $L K \_$mining & $\begin{array}{l}-3.15^{* *} \\
(1.57)\end{array}$ & $\begin{array}{l}-2.22^{* *} \\
(1.02)\end{array}$ & & $\begin{array}{l}-1.25^{* *} \\
(0.63)\end{array}$ & $\begin{array}{c}-8.98^{* * *} \\
(2.89)\end{array}$ \\
\hline & LK_manuf_agr & $\begin{array}{c}-15.48^{* *} \\
(7.99)\end{array}$ & $\begin{array}{l}-9.55^{* * *} \\
(2.99)\end{array}$ & & $\begin{array}{c}-13.08^{* *} \\
(6.72)\end{array}$ & $\begin{array}{l}-18.31^{*} \\
(10.27)\end{array}$ \\
\hline & LK_others & 13.51 & 14.99 & & -1.82 & $15.71^{*}$ \\
\hline & & $(10.17)$ & $(9.72)$ & & $(4.48)$ & $(8.54)$ \\
\hline & LK_mining_agr & & & $\begin{array}{l}-6.27^{*} \\
(3.58)\end{array}$ & & \\
\hline & LK_manuf & & & $-6.33^{*}$ & & \\
\hline & & & & $(3.41)$ & & \\
\hline & LK_others & & & $\begin{array}{c}8.92 \\
(8.28)\end{array}$ & & \\
\hline & Union & $0.03^{*}$ & $0.03^{*}$ & $0.03^{*}$ & $0.09^{* *}$ & $0.06^{*}$ \\
\hline & $B R R$ & $\begin{array}{l}0.36^{* * *} \\
(0.11)\end{array}$ & $\begin{array}{l}0.36^{* * *} \\
(0.11)\end{array}$ & $\begin{array}{l}0.36^{* * *} \\
(0.08)\end{array}$ & $\begin{array}{l}0.31^{* * *} \\
(0.07)\end{array}$ & $\begin{array}{c}0.35^{* * *} \\
(0.09)\end{array}$ \\
\hline & $L L F$ & $\begin{array}{l}-29.81^{*} \\
(15.98)\end{array}$ & $\begin{array}{l}-29.07^{*} \\
(16.23)\end{array}$ & $\begin{array}{l}-21.03 \\
(19.01)\end{array}$ & & $\begin{array}{c}-85.89^{* * *} \\
(27.49)\end{array}$ \\
\hline & Left & $\begin{array}{c}1.11^{* *} \\
0.52\end{array}$ & $\begin{array}{c}1.09^{*} \\
0.56\end{array}$ & $\begin{array}{c}0.99^{*} \\
0.56\end{array}$ & $\begin{array}{c}0.64^{*} \\
0.38\end{array}$ & $\begin{array}{l}0.47 \\
0.39\end{array}$ \\
\hline & Intercept & -59.65 & -26.34 & 68.43 & $-115.49^{* *}$ & $650.73^{* * *}$ \\
\hline & & $(55.61)$ & $(64.16)$ & $(78.19)$ & $(51.48)$ & $(198.45)$ \\
\hline \multirow{7}{*}{ 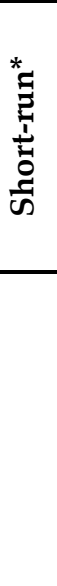 } & $e_{1}(-1)\left(\alpha_{11}\right)$ & $\begin{array}{c}-0.54^{* *} \\
(0.21)\end{array}$ & $\begin{array}{c}-0.58^{* *} \\
(0.25)\end{array}$ & $\begin{array}{l}-0.65^{* *} \\
(0.26)\end{array}$ & $\begin{array}{c}-0.59^{* *} \\
(0.20)\end{array}$ & $\begin{array}{c}-0.91^{* * *} \\
(0.23)\end{array}$ \\
\hline & $e_{2}(-1)\left(\alpha_{21}\right)$ & & $\begin{array}{c}-0.07 \\
0.09\end{array}$ & & & \\
\hline & $\Delta U R(-1)\left(\gamma_{11}\right)$ & $\begin{array}{l}0.43^{* *} \\
(0.19)\end{array}$ & $\begin{array}{l}0.32 \\
(0.20)\end{array}$ & $\begin{array}{l}0.49^{* *} \\
(0.22)\end{array}$ & $\begin{array}{c}0.45^{* * *} \\
(0.17)\end{array}$ & $\begin{array}{c}0.48^{* * *} \\
(0.19)\end{array}$ \\
\hline & \multicolumn{6}{|c|}{ Multivariate Residual Diagnostics } \\
\hline & $\begin{array}{l}\text { Normality } \\
\text { (Jarque-Bera test) }\end{array}$ & $\begin{array}{l}22.11 \\
(0.23)\end{array}$ & $\begin{array}{l}25.76 \\
(0.11)\end{array}$ & $\begin{array}{l}17.81 \\
(0.45)\end{array}$ & $\begin{array}{l}19.09 \\
(0.39)\end{array}$ & $\begin{array}{l}20.53 \\
(0.30)\end{array}$ \\
\hline & $\begin{array}{l}\text { Lag } 1 \text { Autocorrelation } \\
\text { (LM test) }\end{array}$ & $\begin{array}{l}51.44 \\
(0.87)\end{array}$ & $\begin{array}{l}62.79 \\
(0.99)\end{array}$ & $\begin{array}{l}79.36 \\
(0.53)\end{array}$ & $\begin{array}{l}61.39 \\
(0.57)\end{array}$ & $\begin{array}{l}98.56 \\
(0.52)\end{array}$ \\
\hline & $\begin{array}{l}\text { Lag } 2 \text { Autocorrelation } \\
\text { (LM test) }\end{array}$ & $\begin{array}{l}67.39 \\
(0.36)\end{array}$ & $\begin{array}{l}85.66 \\
(0.86)\end{array}$ & $\begin{array}{l}88.69 \\
(0.26)\end{array}$ & $\begin{array}{l}65.47 \\
(0.43)\end{array}$ & $\begin{array}{r}100.03 \\
(0.48)\end{array}$ \\
\hline
\end{tabular}

Note: ${ }^{*}$ insignificant coefficient estimates $(\gamma$ and $\psi$ ) for the short-run component of the model not reported. 
Table 5. Structural model results (equation (16))

\begin{tabular}{|c|c|c|c|c|c|c|}
\hline & & \multicolumn{4}{|c|}{$\begin{array}{l}\text { Panel A: FIML estimates of parameters of the } \\
\text { sectoral production functions }\end{array}$} & \\
\hline & & & Coeff. & Std. err. & Z-stat. & \\
\hline & & $\beta_{X}$ & 0.88 & 0.43 & 2.06 & \\
\hline & & $\beta_{Y}$ & 0.85 & 0.42 & 2.02 & \\
\hline & & $\beta_{N}$ & 0.96 & 0.48 & 2.01 & \\
\hline & & $\Phi$ & 1.31 & 0.53 & 2.49 & \\
\hline & \multicolumn{5}{|c|}{$\begin{array}{l}\text { Panel B: Calibrated estimates of the derivatives of } \\
\text { sectoral labour demands }\end{array}$} & \\
\hline & & & Mean & Std. dev. & Z-stat & \\
\hline & & $G_{1}$ & -0.89 & 0.83 & -7.38 & \\
\hline & & $G_{2}$ & 0.25 & 0.23 & 7.25 & \\
\hline & & $H_{1}$ & -3.28 & 1.05 & -21.45 & \\
\hline & & $\mathrm{H}_{2}$ & 0.58 & 0.53 & 7.60 & \\
\hline & & $J_{1}$ & -2.23 & 1.50 & -10.20 & \\
\hline & & $J_{2}$ & 0.07 & 0.06 & 8.16 & \\
\hline & \multicolumn{6}{|c|}{$\begin{array}{c}\text { Panel C: Calibrated (mean) structural equation } \\
\text { estimates (indirect effects) }\end{array}$} \\
\hline & Mean & Std. Dev. & & & Mean & Std. Dev. \\
\hline$\kappa_{B}$ & 0.02 & 0.02 & & $\tau_{B}$ & 0.00 & 0.00 \\
\hline$\kappa_{p}$ & -0.07 & 0.07 & & $\tau_{p}$ & 0.15 & 0.06 \\
\hline$\kappa_{\lambda}$ & 4.44 & 2.16 & & $\tau_{\lambda}$ & -0.68 & 1.08 \\
\hline$\kappa_{\bar{L}}$ & 0.04 & 0.02 & & $\tau_{\bar{K}_{X}}$ & 0.02 & 0.01 \\
\hline$\kappa_{\bar{K}_{X}}$ & -0.01 & 0.02 & & $\tau_{\bar{K}_{Y}}$ & 0.03 & 0.02 \\
\hline$\kappa_{\bar{K}_{Y}}$ & -0.02 & 0.03 & & $\tau_{\bar{K}_{N}}$ & -0.01 & 0.01 \\
\hline$\kappa_{\bar{K}_{N}}$ & 0.00 & 0.00 & & $\tau_{u}$ & 0.35 & 1.11 \\
\hline$\kappa_{p_{n}}$ & -0.18 & 0.14 & & & & \\
\hline
\end{tabular}

Panel D: Calibrated structural equation estimates (direct effects)

\begin{tabular}{crrrrrr}
\hline & Mean & Median & Max. & Min. & Std. dev. & Z-stat. \\
\hline$B$ & 0.0170 & 0.0101 & 0.0794 & 0.0001 & 0.0179 & 6.511 \\
ToT & -0.1061 & -0.0985 & 0.0000 & -0.3011 & 0.0923 & -7.885 \\
$\lambda$ & 4.4651 & 4.8665 & 7.1485 & 1.0113 & 2.1730 & 14.087 \\
$\bar{L}$ & 0.0375 & 0.0315 & 0.0870 & 0.0006 & 0.0236 & 10.886 \\
$\bar{K}_{X}$ & -0.0112 & -0.0060 & $-3.40 \mathrm{E}-04$ & -0.0908 & 0.0159 & -4.833 \\
$\bar{K}_{Y}$ & -0.0232 & -0.0142 & $-9.01 \mathrm{E}-04$ & -0.1419 & 0.0262 & -6.067 \\
$\bar{K}_{N}$ & -0.0014 & -0.0001 & 0.0024 & $-2.10 \mathrm{E}-02$ & 0.0043 & -2.210 \\
\hline
\end{tabular}


Figure 1. Time series behaviour of $U R, T o T, B R R$ and Union

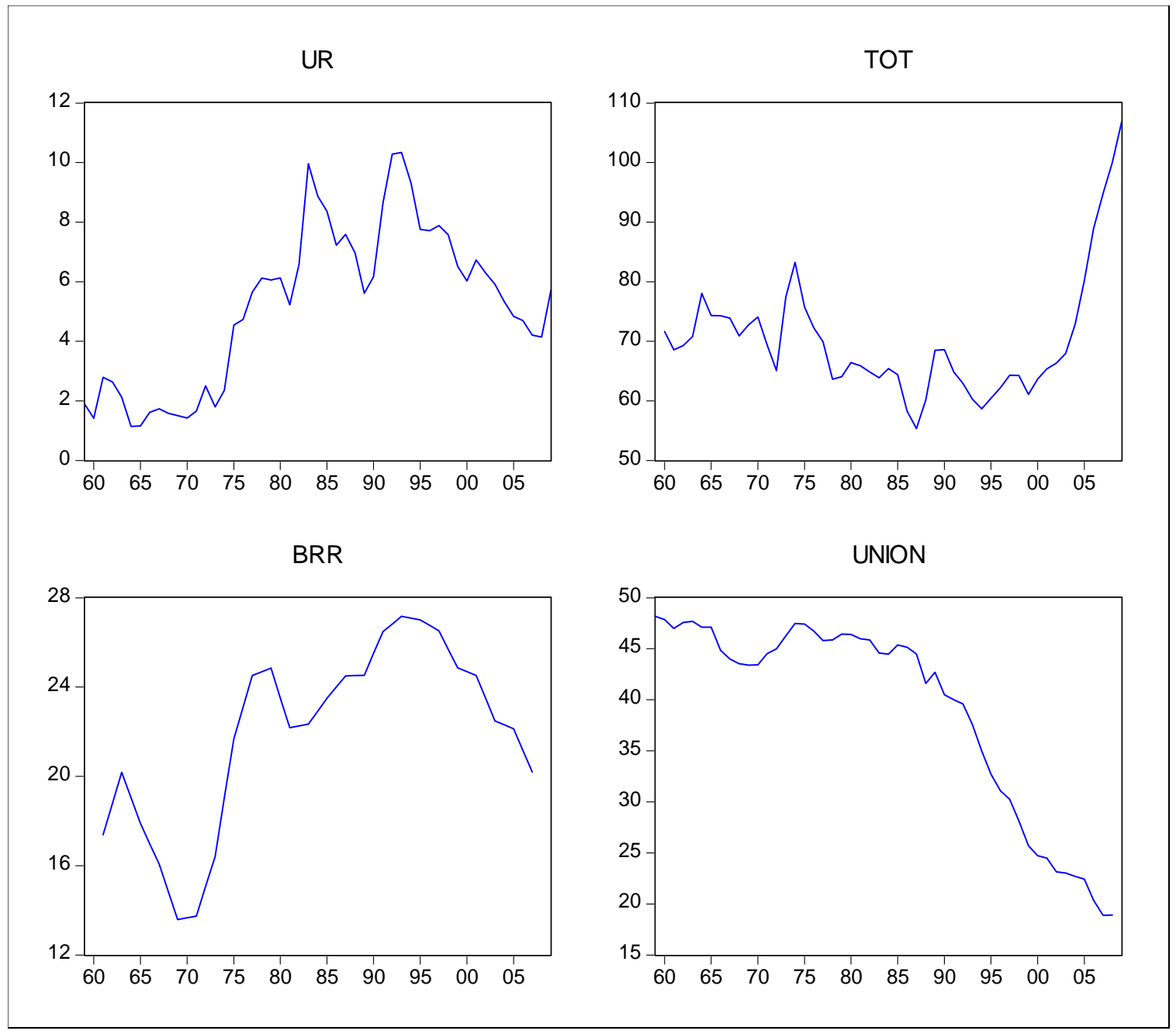


Table A1. Data sources and notes

\begin{tabular}{|c|c|c|}
\hline Label & Source and notes & Period $^{*}$ \\
\hline UR & $\begin{array}{l}\text { From ABS cat. no. } 6202.0 \text { - Labour Force, Australia. June figures. See Table } 03 \text { (Labour force status by Sex). Data for } \\
\text { the labour force }(L F) \text { are also from this source. }\end{array}$ & Fiscal \\
\hline Prices $^{\dagger}$ & $\begin{array}{l}\text { From ABS cat. No. } 5204.0 \text { - Australian System of National Accounts, 2008-09. Table } 2 \text { (Expenditure on Gross } \\
\text { Domestic Product) has data for gross national expenditure (domestic absorption), exports and imports both at } \\
\text { current prices as well as chain volume measures. The deflators are calculated to obtain prices for non-tradeable } \\
\left(\boldsymbol{P}_{\mathrm{N}}\right) \text {, export and import goods and services }\left(\boldsymbol{P}_{\mathrm{x}} \text { and } \boldsymbol{P} \text { ), respectively. The implicit price deflators are indexed with }\right. \\
\text { a reference year June } 2008=100 . T \text { To } T \text { is the ratio of export prices to import prices. }\end{array}$ & Fiscal \\
\hline Capital stock $\ddagger$ & $\begin{array}{l}\text { From ABS cat. no. } 5204.0 \text { - Australian System of National Accounts, 2008-09. Table } 58 \text { (Capital Stock, by Industry) } \\
\text { contains data for net capital stock (chain volume measures). }\end{array}$ & Fiscal \\
\hline Union & $\begin{array}{l}\text { Up to 1996, trade union membership was reported by unions and published by the ABS in its annual Labour } \\
\text { Reports publications, and then in cat. no. } 6323.0 \text { Trade Union Statistics, Australia. Unionisation rates measured as } \\
\text { membership divided by the labour force. From 1990, unionisation rates are available on a survey basis from ABS } \\
\text { cat. no. } 6310.0 \text { Employee Earnings, Benefits and Trade Union Membership, Australia (Trade Union Membership } \\
\text { Time Series). }\end{array}$ & $\begin{array}{l}\text { Fiscal (June } 30 \\
\text { up to 1989; } \\
\text { August figure } \\
\text { from 1990) }\end{array}$ \\
\hline$B R R^{\S}$ & $\begin{array}{l}\text { The measure is defined as the average of the gross unemployment benefit replacement rates for two earnings levels, } \\
\text { three family situations and three durations of unemployment (see, Martin, 1996). Pre-2003 data have been revised. }\end{array}$ & Calendar \\
\hline
\end{tabular}

Notes: ABS = Australian Bureau of Statistics. ${ }^{*}$ Fiscal data are for financial years (e.g., data for 1991 means 1 July, 1991 to 30 June, 1992$)$. Calendar data are for calendar years (e.g., data for 1991 means 1 January, 1991 to 31 December, 1991), converted to fiscal by averaging two adjacent years (e.g., 1991 is the average of 1991 and 1992 figures). The advice of Katrina Watts $\left(^{\dagger}\right)$ and Stephen Waugh $(\ddagger)$ of the ABS is gratefully acknowledged. § Herwig Immervoll, Head of Employment-Oriented Social Policies at the OECD generously provided these data. ¥ Industries: agriculture, forestry and fishing; mining; manufacturing; electricity, gas and water supply; construction; wholesale trade; retail trade; accommodation, cafes and restaurants; transport and storage; communication services; finance and insurance; property and business services; government administration and defence; education; health and community services; cultural and recreational services; personal and other services. 